\title{
Benchmarking for Routines and Organizational Knowledge: A Managerial Accounting Approach with Performance Feedback
}

\author{
Mircea Epure \\ Department of Economics and Business \\ Universitat Pompeu Fabra, Barcelona GSE and Barcelona School of Management \\ Ramon Trias Fargas, 25-27, E-08005 Barcelona, Spain \\ Phone: +34 93542 2546, Fax: +34 935421746 \\ mircea.epure@upf.edu
}

This version: February 2016

\begin{abstract}
This study proposes a managerial accounting research design that bridges a gap between firm productivity based on frontier techniques and strategic management. In doing so, it operationalizes the theoretical frameworks based on the endogenous components of acrossfirms heterogeneous resources and routines, which are fundamental for firm performance. The design focuses on industry-level benchmarking to analyze changes in performance and organizational knowledge investments, and proposes some indicators for firm-level strategic benchmarking. An analysis of a twelve-years panel of the U.S. technology hardware and equipment industry illustrates the usefulness of the proposals. Findings reveal wider gaps between better and worse performers following economic distress. Increasing intangibles stocks is positively associated with changes in frontier benchmarking, while enhancing $R \& D$ spending is linked to frontier shifts. The discussion develops managerial interpretations suitable for control and reward systems.
\end{abstract}

Keywords: benchmarking; resources; management accounting; organizational investments; frontier analysis 


\section{INTRODUCTION}

This study adopts a managerial accounting perspective to propose and empirically illustrate a research design for firm decision making based on performance feedback. In doing so, it bridges a gap between studies on firm productivity based on frontier techniques and strategic management. By using best practice benchmarking to assess firm outcomes, the analysis accounts for the endogenous components of across-firms heterogeneous routines (Winter 2003; Abell et al. 2008; Felin and Foss 2011; Argyres et al. 2012). ${ }^{1}$ This approach is grounded in the managerial accounting task of performance monitoring for control and reward systems (Ittner and Larcker 1997; Kaplan and Atkinson 2000; Balk 2003; Langfield-Smith 2005; Smith 2005).

Balk (2003) describes productivity measures and frontier efficiency benchmarking that can be used for target setting and control. In related contributions, Agrell et al. (2002) and Bogetoft and Otto (2011) show how frontier benchmarking can be used to elicit information for organizational learning and knowledge enhancement, as well as for establishing yardstick compensation measures. These methods can be used for inter- or intra-firm control and reward, and are closely linked with incentive plans and information systems for control in principal-agent models (Antle et al. 2001; Bogetoft and Olesen 2003).

Investing in information and control systems fosters learning, and can enhance organizational routines and knowledge that are crucial for long-term success (Agrell et al. 2002; Bogetoft and Olesen 2003; Knott 2003; Knott and Posen 2009). Following managerial accounting rationales, changes in organizational knowledge can be proxied using benchmarking techniques which yield outcomes vis-à-vis industry competitors, thus showing if the firm is using the best or worst practices (Camp 1995, 1998; Balk 2003).

\footnotetext{
${ }^{1}$ Note that "routines" is the usual management theory of the firm terminology, while managerial accounting and productivity literature generally refers to "practices”. In this paper, the two terms are equivalent.
} 
Seeking practices for target setting, control and organizational improvementbenchmarking—is a core managerial task commonly characterized as a problem solving activity, generally implemented through response actions to business analytics feedback (Camp 1995; Ittner and Larcker 1997; Greve 2003; Kaplan and Atkinson 2000). Studies that benchmark performance using organizational routines and knowledge rationales are rare, probably because the usual focus is on learning how to use, not to change, existing practices (Greve 2003). Moreover, strategy research suggests that bad outcomes shift decision makers' attention from improving practices to pursuing bold and hasty actions (Bromiley et al. 2001).

Benchmarking reveals the gap between the firm's resources and routines and those of competitors. Catching up to competitors or strengthening a competitive advantage can be pursued by investing in organizational knowledge, usually proxied through research and development (R\&D) spending and intangible assets. R\&D can be a driver of growth (Romer 1990) and leads to competitive advantages especially in high-technology markets (Dutta et al. 1999). However, R\&D itself does not enhance productivity, which is positively related to innovations fostered by R\&D (Acs et al. 2009). Such innovations may be better captured via accumulated intangible assets, while generally assets' accumulation can be a consequence of business model choices (Casadeus-Masanell and Ricart 2011). Given that intangible assets can be imitated, catching up to best practices (the frontier) can occur (Knott et al. 2003).

Performance changes can be related to learning and variations in organizational knowledge, which is embedded in resources and routines (Penrose 1959; Wernerfeldt 1984; Barney 1991; Teece et al. 1997; Teece 2007). Importantly, resources and routines are heterogeneous across firms (Teece et al. 1997; Winter 2003; Abell et al. 2008; Argyres et al. 2012; Felin et al. 2012). Benchmarking information is especially relevant in this case since it gauges information on endogenous firm routines and compares them to the results of heterogeneous competitors (Agrell et al. 2002 and Bogetoft and Otto 2011). In this sense, 
catching up to best practices has endogenous components that originate in organizations (Felin and Foss 2011), while assessments are not shaped only by the firm's resources, but also by the ability to assess the resources and performance of others firms (Denrell et al. 2003).

This study contributes to the literature in at least two ways. First, it proposes a managerial accounting design with performance feedback that bridges a gap between studies on firm productivity based on frontier techniques and strategic management. The research design uses frontier-based information systems for control and reward (Agrell et al. 2002; Bogetoft and Otto 2011) to capture the endogenous components of across-firms heterogeneous routines (Winter 2003; Abell et al. 2008; Felin and Foss 2011; Argyres et al. 2012). Specifically, it assesses changes in firm results and their link to shifts in organizational knowledge investments. Frontier measures are employed for industry-level organizational benchmarking, and some new indicators are proposed for firm-level strategic benchmarking.

Second, it empirically demonstrates the research design's usefulness for management and accounting theory, and for managers in search of profitability analyses. Findings from a twelve-years panel of the U.S. technology hardware and equipment industry reveal wider gaps between better and worse performers following economic distress. Also, increasing intangibles stocks is positively associated with changes in frontier benchmarking, while enhancing $R \& D$ spending is positively linked to frontier shifts. The discussion of the results provides managerial interpretations suitable for control and reward systems (Ittner and Larcker 1997; Kaplan and Atkinson 2000; Balk 2003). Finally, the sensitivity of benchmarking measures to managerial discretion over flow or stock variables is scrutinized.

The rest of the paper is structured as follows. Section 2 provides the conceptual framework. Section 3 proposes the research design. Methodological details on benchmarking measures and their fit with heterogeneous routines are presented jointly with the analysis stages and data in Section 4. The results are discussed in Section 5, while Section 6 concludes. 


\section{RELATED LITERATURE}

\subsection{Routines, organizational knowledge and performance}

The resource-based view of the firm and related routines-based framework(s) are mainstream theoretical approaches in the strategic management literature. ${ }^{2}$ Existing studies focus on the unique bundle of resources (i.e. inputs) that firms possess and analyze the organizational routines expected to generate competitive advantages and performance differences (Penrose 1959; Wernerfeldt 1984; Barney 1991; Teece et al. 1997; Teece 2007). Knowledge embedded in routines can lead to combining existing resources in novel ways, and the routines' valuation depends on the firm's resources and its ability to gauge the resources and performance of other firms (Denrell et al. 2003). A gap remains with respect to operationalizing these frameworks, especially in the case of using accounting information (Denrell et al. 2003; Foss and Ishikawa 2007).

A growing body of literature considers the dynamic nature of resources and routines (Teece et al. 1997; Zollo and Winter 2002; Winter 2003; Zott 2003; Teece 2007; Abell et al. 2008; Argyres et al. 2012). Ongoing debates critically assess the dynamic aspect of the frameworks and propose alternatives (e.g. Denrell et al. 2003; Winter 2003; Foss and Ishikawa 2007; Abell et al. 2008; Argyres et al. 2012), whereas some consensus exists on the fact that the dynamic components of routines are sustained and enhanced by organizational knowledge (Teece 2007; Zollo and Winter 2002; Augier and Teece 2007). Importantly, it is well established that routines are endogenous to firms and heterogeneous across firms (Teece et al. 1997; Winter 2003; Abell et al. 2008; Argyres et al. 2012; Felin et al. 2012).

The mechanisms through which routines may enhance performance are not straightforward (Zollo and Winter 2002). Nevertheless, it is generally agreed that firms that possess the appropriate knowledge on routines are more efficient, can more easily enhance

\footnotetext{
${ }^{2}$ See Foss and Stieglitz (2011) for a critical review of the RBV. One can refer to Argyres et al. (2012) for the relationship between the routines literature and organizational economics, with special focus on heterogeneity.
} 
their performance by altering their resource base, and competitors cannot straightforwardly imitate their practices (Helfat and Peteraf 2003; Foss and Stieglitz 2011).

In this sense, routines reflect past knowledge, and the learnt patterns are drivers of competitive advantage, which is an antecedent of performance (Foss and Stieglitz 2011). An upward shift in performance could be indicative of organizational knowledge enhancements, which are arguably influenced by R\&D spending and intangible assets (e.g. Knott 2003; Knott et al. 2003; Knott and Posen 2009). Conversely, negative feedback may stimulate exploring new resource combinations (Denrell et al. 2003; Greve 2003). This can be done via R\&D flows (and their accumulation into intangibles), which are usually positively correlated with performance (e.g. Capon et al. 1990; Ettlie 1998; Griliches 1998; Blundell et al. 1999; Dutta 1999; O’Mahony and Vecchi 2009).

\subsection{Benchmarking as a route to enhanced organizational knowledge}

Firms learn from performance feedback, which is directly linked to acquiring organizational knowledge. This process is crucial for strategic planning and enhancing competitive advantages in dynamic contexts. Indeed, firms must be able to "reconfigure internal and external competences to address rapidly changing environments” (Teece et al. 1997: 516) and "systematically generate and modify operating routines in pursuit of improved effectiveness” (Zollo and Winter 2002: 340). Strategic management and productivity studies often tackle these issues through best practice benchmarking (Camp 1995, 1998; Balk 2003).

In its purest form, benchmarking is the selection of a unit of strategic value against which performance is compared (Camp 1998). Firms can so set goals, deduce whether they have best or worse practices, and aim at maintaining superiority or closing the gap to competitors (Camp 1995, 1998; Smith 2005). There are two purposes that research designs should not miss: provide valuable feedback on past performance (internal monitoring) jointly with information on competitors' performance and practices (external benchmarking) (Balk 
2003). Accordingly, benchmarking can be utilized for data analysis and target setting prior to selecting strategies, but also as part of the management control and reward systems (Ittner and Larcker 1997; Kaplan and Atkinson 2000; Balk 2003; Langfield-Smith 2005; Smith 2005). While benchmarking primarily aims at increasing performance, it also fosters organizational knowledge by facilitating the learning of (best) practices (Camp 1995, 1998; Smith 2005).

To operationalize these conceptual approaches, managerial studies usually turn to output to input productivity ratios (i.e. $y / x$ ) or profitability given by accounting data (see Banker et al. 1996; Kaplan and Atkinson 2000; Balk 2003; Banker et al. 2007; Epure et al. 2011). In the absence of price effects, productivity coincides with profitability, which is the usual concern of managers (Balk 2003). Productivity change between periods $t$ and $t+1$ is given by $\left(y^{t+1} / x^{t+1}\right) /\left(y^{t} / x^{t}\right)$ or, using differences, by $\left(y^{t+1} / x^{t+1}\right)-\left(y^{t} / x^{t}\right)$, which in the presence of prices or aggregated accounting data yields a joint measure of output and price effects, that is, profitability (see, e.g., Grifell-Tatjé and Lovell 1999; Kaplan and Atkinson 2000). A differences-based accounting approach computes profit $(\pi)$ as output quantity $(y)$ multiplied by output price $(p)$ minus input quantity $(x)$ multiplied by input cost $(w)$, and thus profit change is: $\left.\pi^{t+1}-\pi^{t}=\left(y^{t+1} p^{t+1}-x^{t+1} w^{t+1}\right)-\left(y^{t} p^{t}-x^{t} w^{t}\right)\right)$.

In multidimensional settings there are various issues that these single output to input ratios or differences do not address. Dissimilar results may appear, as ratios are constructed to reveal a certain characteristic of performance. Managers could thus be unable to identify benchmarks as they are facing dilemmas raised by the multiple interpretations and potentially contradictory results (Camp 1995). Yet another issue is that one-dimensional output to input ratios many times lack an underlying theoretical model, and therefore it may be difficult to understand their mechanisms.

The productivity and efficiency literature solves these problems by using nonparametric frontier methods that accommodate multiple outputs and inputs (see Ray (2004) 
for technical details). Frontier-based assessments represent a more sophisticated technique to benchmark relative performance, as they compute the degree of inefficiency separating a firm from the best practice frontier. The benchmarks are the efficient firms that shape the frontier and against which all the other units are projected. This is a more theoretically sound method, which is also easier to interpret since it employs a model with underpinnings in production theory. Moreover, it can be adapted to dynamic analyses that capture frontier shifts through indices or indicators. To maintain the proximity to managerial accounting, this study employs a difference-based indicator, which is decomposed into managerial and frontier (industry) effects. Furthermore, new components for individual firm benchmarking are proposed.

\section{A DESIGN WITH ROUTINES AND PERFORMANCE FEEDBACK}

Figure 1 starts from the model on resources and routines discussed by Abell et al. (2008). The proposed model is then developed to present a comprehensive image of routines and organizational influences on firm performance by focusing on the dynamics of feedback and investments in organizational knowledge. In Figure 1, the arrows show the shorter or longer paths for analyzing firm performance. For macro elements, arrow 4 is sufficient and is usually the path followed by one-dimensional analyses (e.g. studies based on financial accounting ratios). This aggregated approach is appropriate at industry and economy levels. At firm level, endogenous mechanics and across-firms heterogeneity play important roles.

[Figure 1 about here]

The endogenous dynamics (Felin and Foss 2011) and heterogeneous routines (Teece et al. 1997; Winter 2003; Abell et al. 2008; Argyres et al. 2012; Felin et al. 2012), which are accounted for by the performance benchmarking method (see next section), make the emphasis shift towards firm foundations scrutinized through the arrows 1 to $3 .^{3}$ Each time

\footnotetext{
${ }^{3}$ Abell et al. (2008) provide an in-depth perspective (including a modeling effort) on the foundations of routines and their link to performance. Note that these authors upgrade the model of Coleman (1990) by introducing arrow 1a. This study interprets this relationship slightly differently given its different focus.
} 
period starts from existing routines, given organizational knowledge and related investments. These are used in conjunction with resources (inputs) (arrow 1), understood sometimes as micro-level conditions. The value-creating activities materialize from arrows $1 \mathrm{a}$ and 2 to indicate the combination between known routines and their interaction with available resources (inputs). Each period ends with the net outcome of operating processes (arrow 3) and, when benchmarking, results show distances to competitors.

Note that, apart from operating processes, Figure 1 isolates an organizational knowledge effect at the end of each period. In line with managerial accounting approaches, these knowledge investments (arrow 0) occur as a function of feedback and learning from the previous period ( $t-1)$ and affect the routines of the analyzed period $(t)$. Benchmarking information is crucial for end-period feedback, since decision making at this level is usually based not only on own performance, but also—and perhaps more importantly—on information on competitors and industry practices. In this sense, arrow 0 is an antecedent of routines in a dynamic model for a knowledge economy and can be a source of flexibility and change (see Foss 2005). The bigger picture of this design is the sequence of firm operations and outcomes preceded (and followed) by changes in organizational knowledge. Decision makers are interested in outcomes' changes, which are revealed by scrutinizing shifts in subsequent periods’ results. Moreover, changes in knowledge investments between $t-1$ and $t$ are expected to influence routines and performance variations between $t$ and $t+1$, which are related to ensuing organizational investments. ${ }^{4}$

Note that this approach can be related to network Data Envelopment Analysis (DEA) methods (Färe et al. 2007). However, in this study, knowledge investments are not an intermediate product per se, rather they represent a firm decision that depends on the results of the period. In this case, knowledge investments can decrease, remain stable or increase,

\footnotetext{
${ }^{4}$ Felin et al. (2012) propose to extend the research agenda on the foundations of routines, and in doing so they enter the process of sequential time periods' influences on organizational routines.
} 
whereas in network DEA models there is usually an intermediate product that is maximized or minimized. Allowing for heterogeneous firm-level investment decisions based on performance feedback is a key concern for the operationalization of Figure 1.

\section{BENCHMARKING INDICATORS, ANALYSIS STAGES AND DATA}

\subsection{Benchmarking indicators: specification, interpretations and some proposals}

This section presents the Luenberger indicator that is employed for operationalizing the linkages of arrows 1 to 3 from Figure 1. Moreover, it provides the solution to accounting for firm endogenous and across-firms heterogeneous routines, and some proposals for firm-level strategic benchmarking. Firm outcomes are first assessed in a given time period, and then inter-temporal indicators provide changes in results to match the dynamic research design.

Chambers et al. (1996) introduced the Luenberger productivity indicator as a difference of directional distance functions. Whereas the academic community is more familiar with ratios, the business and accounting communities are more accustomed to evaluating cost, revenue, or profit differences (Boussemart et al. 2003). Another advantage of the Luenberger indicator is that, instead of specializing in either input- or output-orientation, it addresses input contractions and output expansions simultaneously and is therefore compatible with the economic goal of profit maximization, which is usually pursued in managerial accounting settings as well as in economic theory (Boussemart et al. 2003). ${ }^{5}$

Let $\mathbf{x}=\left(x_{1}, \ldots, X_{N}\right) \in R_{+}^{N}$ and $\mathbf{y}=\left(y_{1}, \ldots, y_{M}\right) \in R_{+}^{M}$ be the vectors of inputs and outputs, respectively. Technology is defined by $T^{t}\left(\mathbf{x}^{t}, \mathbf{y}^{\mathbf{t}}\right)$, which represents the set of all output vectors $\left(\mathbf{y}^{\mathbf{t}}\right)$ that can be produced using the input vector $\left(\mathbf{x}^{\mathbf{t}}\right)$ in the time period $t$ :

$T^{t}\left(\mathbf{x}^{\mathbf{t}}, \mathbf{y}^{\mathbf{t}}\right)=\left\{\left(\mathbf{x}^{\mathbf{t}}, \mathbf{y}^{\mathbf{t}}\right): \mathbf{x}^{\mathbf{t}}\right.$ can produce $\left.\mathbf{y}^{\mathbf{t}}\right\}$

\footnotetext{
${ }^{5}$ Given the duality between the profit function and the directional distance function (Luenberger 1992; Chambers et al. 1998), in the presence of data on quantities and prices, profit efficiency could be estimated and decomposed into technical and allocative efficiency. In this study however, data on prices and quantities cannot be well identified and therefore the Luenberger indicator is specified in terms of inputs and outputs.
} 
This technology assumes variable returns to scale (VRS), convexity and strong disposability of inputs and outputs. Assuming VRS is a key aspect for strategic benchmarking since results must reflect changes due to changes in managerial practices or frontier shifts. ${ }^{6}$ VRS resultscontrary to the constant returns to scale (CRS) ones-isolate managerial practices' outcomes from scale effects. Furthermore, to test whether VRS better represents firm inefficiencies, the results’ section presents tests of model assumptions following Bogetoft and Otto (2011). In particular, this assumption is verified using Kolmogorov-Smirnov tests of equality of distributions between inefficiency scores calculated under VRS and CRS.

Choosing the distance function is crucial for the research design. Its specification must satisfy the requirements of the management literature that calls for the use of endogenous data jointly with accounting for across-firms heterogeneous configurations. To achieve these goals and integrate benchmarking information on competitors, the proportional distance function proposed by Briec (1997) is used. The score of firm $k$ ' in period $t$ is computed as:

$D^{t}\left(x^{t}, y^{t}\right)=\left\{\max \delta:\left((1-\delta) x_{k}^{t},(1+\delta) y_{k}^{t}\right) \in T^{t}\left(\mathbf{x}^{\mathrm{t}}, \mathbf{y}^{\mathrm{t}}\right)\right\}$.

or as the solution to the following linear programming problem:

$$
\begin{aligned}
D^{t}\left(x^{t}, y^{t}\right)= & \max \\
& \left\{\delta: \sum_{k=1}^{K} \lambda_{k}^{t} y_{k m}^{t} \geq y_{k^{\prime} m}^{t}+\delta y_{k^{\prime} m}^{t}, \quad(m=1,2, \ldots, M),\right. \\
& \sum_{k=1}^{K} \lambda_{k}^{t} x_{k n}^{t} \leq x_{k^{\prime} n}^{t}-\delta x_{k^{\prime} n}^{t}, \quad(\mathrm{n}=1,2, \ldots, N), \\
& \left.\sum_{k=1}^{K} \lambda_{k}=1, \lambda_{k} \geq 0, \quad(k=1,2, \ldots, K)\right\} .
\end{aligned}
$$

This frontier-based distance function completely characterizes technology at period $t$ and estimates the simultaneous expansion in all outputs and contraction in all inputs. A result of zero designates efficient units, while scores higher than zero indicate the degree of

\footnotetext{
${ }^{6}$ Chambers and Pope (1996) argue that restricting the returns to scale to constant should be avoided unless one analyses firms in long run equilibrium.
} 
inefficiency. ${ }^{7}$ The proportional distance function is a specific case of the directional distance function introduced by Chambers et al. (1996), which can have different specifications depending on the choice of the directional vector. In equation (3), the vector is defined as $\mathrm{g}=$ $(x, y)$ which, when multiplied by $100 \%$, is the percent contraction (expansion) in inputs (outputs). One could also use $\mathbf{g}=(1,1)$ to obtain the maximum unit expansion in all outputs and simultaneous unit contraction in inputs. Another of the many possibilities may be a vector $\mathbf{g}=(x, 0)$, which yields the percentage contraction in inputs, holding all outputs fixed.

Recent contributions propose more sophisticated approaches to specifying the directional vector. Daraio and Simar (2014) introduce a data-driven approach to set the direction of the inefficiency measure. This proposal is especially relevant for context specific (or local) directions of firms and allows for various levels of managerial discretion over inputs or outputs. In this case, the algorithm looks for “a local direction that accounts for possible heterogeneity measured by some exogenous contextual factors” (Daraio and Simar 2014: 6). In related work, Zofio et al. (2013) endogenize the value of the directional vector to take inefficient units to the profit maximizing benchmark, which is common for all firms.

Among the various existing alternatives, the proportional distance function matches the objectives of the study and the framework in Figure 1. The distance function must capture endogenous dynamics (Felin and Foss 2011) and heterogeneous routines (Teece et al. 1997; Winter 2003; Abell et al. 2008; Argyres et al. 2012; Felin et al. 2012). First, to account for the heterogeneity across firm configurations and decisions, the direction should not be common for all firms, as it is in the case of more traditional directional distance functions. Second, the frontier benchmarks should be different depending firm characteristics, as opposed to the unique benchmark proposed by Zofio et al. (2013). Third, in this study’s case (see Figure 1 and Section 3) the source of heterogeneity across firms is given by the

\footnotetext{
${ }^{7}$ See Briec (1997) for further technical aspects.
} 
endogenous characteristics of firms, rather than by exogenous contextual factors as in the proposal of Daraio and Simar (2014). Overall, the proportional distance function matches the objectives and framework since it has a unit-specific orientation, and its estimations reflect characteristics that are endogenous to each firm and heterogeneous across firms, as required by the organizational perspectives in Figure 1 and Section 3.

Assuming a simple technology with only one output and one input, Figure 2 illustrates firm $k$ in periods $t$ and $t+1$, jointly with the corresponding best practice frontiers. The firm is not on the frontier and its distance to the frontier has increased in period $t+1$. Importantly, the direction towards the frontier is given by the firm's ratio of output to input, thus using endogenous information for each firm in each time period. These directions correspond to the firms' endogenous configuration of resources, and thus are heterogeneous across firms.

[Figure 2 about here]

Next, the distance functions can be used to compute changes between periods relative to the frontier. Accordingly, the Luenberger indicator is given by (Chambers et al. 1996):

$$
L^{t}\left(x^{t}, y^{t}, x^{t+1}, y^{t+1}\right)=D^{t}\left(x^{t}, y^{t}\right)-D^{t}\left(x^{t+1}, y^{t+1}\right) .
$$

Equation (4) represents a period $t$ Luenberger indicator, which computes the difference between distance functions evaluating firms in periods $t$ and $t+1$ with respect to the frontier in period $t$. Results greater (lower) than zero indicate productivity increases (decreases). ${ }^{8}$

Due to the managerial implications of this study, one technical consideration is necessary. Briec and Kerstens (2009a; 2009b) show that, especially when assuming VRS (whereas CRS can be a necessary but not a sufficient condition), the Luenberger indicator (or generally the Malmquist-type indices) can yield infeasible results due to projecting inputs and outputs in period $t+1$ on the frontier in $t$. This implies that managers may not always be able

\footnotetext{
${ }^{8}$ Alternative specifications of the indicator use an arithmetic mean to avoid the arbitrary selection of a base year (Chambers et al. 1996). Nonetheless, this method is less suitable for strategic benchmarking which requires a clear target. Using a technology based on a certain year $(t)$ is common in the benchmarking literature (see a related discussion in Epure et al. (2011)). A well-determined frontier is needed since most times managers attempt to understand their competitive environment at a certain point and then assess firms.
} 
to obtain the desired firm-level results. Epure et al. (2011) discuss in more detail the managerial aspects of infeasible results and propose using the Hicks-Moorsteen total factor productivity index. However, due to the generality of this proposal and empirical analysis for the management and accounting communities, and the technical difficulties in decomposing the Hicks-Moorsteen index, the Luenberger indicator is preferred. Another option used in the frontier efficiency literature, is the Malmquist-Luenberger index. This index was initially defined to incorporate undesirable outputs (which is not this study's case), and its global technology specification tackles the problem of infeasible results. A global technology is more suitable for environmental-related objectives rather than managerial accounting analyses, and furthermore Aparicio et al. (2013) discuss various limitations of the MalmquistLuenberger index. In the present study, the infeasibilities are not a crucial issue and are of only $0.2 \%$ of the analyzed sample (5 out of 2354 observations). Taking all these arguments together, in what follows the Luenberger indicator is decomposed and interpreted.

The catching up effects and the impact of the frontier shift, critical for dynamic analyses, are introduced by decomposing the Luenberger indicator into two main components:

$$
\begin{aligned}
L^{t}\left(x^{t}, y^{t}, x^{t+1}, y^{t+1}\right) & =\left[D^{t}\left(x^{t}, y^{t}\right)-D^{t+1}\left(x^{t+1}, y^{t+1}\right)\right]+\left[D^{t+1}\left(x^{t+1}, y^{t+1}\right)-D^{t}\left(x^{t+1}, y^{t+1}\right)\right] \\
& =E C+F C,
\end{aligned}
$$

where the first difference expresses the efficiency change (EC) between periods $t$ and $t+1$ and the second difference represents the frontier change (FC) between periods $t$ and $t+1 .^{9}$

EC measures the evolution of the position of the firm relative to a changing frontier. Specifically, EC evaluates the firms in periods $t$ and $t+1$ relative to the frontier in the corresponding periods. This catching up or falling behind changing industry results is often interpreted as good/bad managerial routines in dynamic settings. This is of course a proxy measure, as this study—like many others—-lacks a direct indicator of management quality. FC measures the shift of the yardstick (i.e. the frontier capturing the progress or regress of peers)

\footnotetext{
${ }^{9}$ This decomposition is similar to that of the Malmquist index (see Färe et al. 1994).
} 
with respect to the evaluated firm. It captures the difference between the distances from the firm in period $t+1$ to the frontier in $t$ and $t+1$. That is, EC is a proxy measure of changes in endogenous routines relative to the routines of best practice firms of the industry in the corresponding year (i.e. catching up), whereas FC reveals differences in the routines that peers employ (i.e. frontier shift). Positive or negative signs of EC and FC represent improvement or deterioration of firm results (catching up or falling behind) and frontier (industry) shifts, respectively. Results of zero show that no changes occurred.

Figure 2 can be used to describe EC and FC. On the one hand, EC is the distance from where firm $k$ is situated in period $t\left(\left(x_{k}^{t}, y_{k}^{t}\right)\right)$ to the frontier in $t\left(D^{t}\left(x^{t}, y^{t}\right)\right)$ minus the distance from the firm in $t+1\left(\left(x_{k}^{t+1}, y_{k}^{t+1}\right)\right)$ to the frontier in $t+1\left(D^{t+1}\left(x^{t+1}, y^{t+1}\right)\right)$. On the other hand, FC can be observed graphically as the shift of the frontier between periods $t$ and $t+1$. In Figure 2, one can observe that $D^{t}\left(x^{t}, y^{t}\right)$ is greater than $D^{t}\left(x^{t+1}, y^{t+1}\right)$, which indicates that results in $t+1$ are superior with respect to the frontier target in $t$. The difference between these two distance functions is the Luenberger indicator $\left(L^{t}\left(x^{t}, y^{t}, x^{t+1}, y^{t+1}\right)\right)$, which in this case illustrates a positive change in frontier $t$ benchmarking. It may be that while firm $k$ moved closer to the frontier in $t$, other industry peers moved even closer or surpassed it. Figure 2 also shows that $D^{t}\left(x^{t}, y^{t}\right)$ is smaller than $D^{t+1}\left(x^{t+1}, y^{t+1}\right)$, a negative result in the EC component. Thus, the overall Luenberger indicator improvement is not maintained when frontier shifts are introduced. A negative EC means that the distance to the corresponding period frontier has increased, indicating a falling behind relative to the industry. The frontier shift (FC), given by $D^{t+1}\left(x^{t+1}, y^{t+1}\right)-D^{t}\left(x^{t+1}, y^{t+1}\right)$, is positive in the case of Figure 2 and may indicate, e.g., innovation or routines’ enhancements in firms with similar configurations.

A new decomposition of the EC component is now proposed to extend the usual disentangling to integrate firm-level benchmarking, thus allowing for comparisons against certain competitors. This approach is attractive to managers who do not want to benchmark 
only against some general industry best practice, but also compare their firm to a certain competitor. ${ }^{10}$ To give just a few examples, this competitor may well be a market segment rival, a member of the same strategic group or simply the geographically closest peer. A first alternative of the decomposition considers a static comparison between an analyzed unit and a benchmark (indicated by the subscript $B$ ):

$$
E C=\left[D^{t+1}\left(x_{B}^{t+1}, y_{B}^{t+1}\right)-D^{t+1}\left(x^{t+1}, y^{t+1}\right)\right]-\left[D^{t}\left(x_{B}^{t}, y_{B}^{t}\right)-D^{t}\left(x^{t}, y^{t}\right)\right]+\left[D^{t}\left(x_{B}^{t}, y_{B}^{t}\right)-D^{t+1}\left(x_{B}^{t+1}, y_{B}^{t+1}\right)\right] .
$$

Equation (6) has three components. The first one measures the variance from the benchmark to the analyzed unit in $t+1$, while the second one does the same for period $t$. In both cases, positive/negative results point to better/worse outcomes as compared to the established benchmark. The third component is simply the efficiency change (EC) of the benchmark firm (which can also be compared against the previously computed EC of the analyzed firm (see equation (5)). While this decomposition offers important insights, it is of a static nature and thus it either requires using data on the previous period or on the current one. Using prior data may lead to obsolete interpretations, and current data may not be available for the benchmark firm. To introduce the dynamic component and reach a more realistic approach a second EC decomposition alternative is:

$$
E C=\left[D^{t}\left(x_{B}^{t}, y_{B}^{t}\right)-D^{t+1}\left(x^{t+1}, y^{t+1}\right)\right]+\left[D^{t}\left(x^{t}, y^{t}\right)-D^{t+1}\left(x_{B}^{t+1}, y_{B}^{t+1}\right)\right]-\left[D^{t}\left(x_{B}^{t}, y_{B}^{t}\right)-D^{t+1}\left(x_{B}^{t+1}, y_{B}^{t+1}\right)\right] .
$$

The three components in equation (7) focus on comparing the firm in the current period against a target set in a previous (or base) period. This analysis is conceptually sound and realistic given that managers usually set targets at a certain point in time, which are then used for control and reward systems in the subsequent period. Accordingly, positive results in the first component of equation (7) indicate that the firm in $t+1$ is superior to the benchmark in $t$. The second component offers an equivalent (mirror) image from the point of view of the benchmark, while the third one—similarly to equation (6) — is the EC of the benchmark.

\footnotetext{
${ }^{10}$ This rationale is similar to Epure et al. (2011). This proposal is however fundamentally different in employing the benchmarking frontier and using endogenous firm data, which yield new decompositions and interpretations.
} 


\subsection{Second stage analysis}

The first stage of the analysis presented a way to tackle the changes in outcomes given by successive firm operations illustrated — for each period — in Figure 1 via the paths of arrows 1 to 3 (see the research design in Figure 1). Second stage regression analyses reveal the relationship between these shifts in performance and organizational knowledge investments, thus focusing on the response to feedback. These investments may take the form of spending (flows) or stock accumulations, and are identified by arrow 0 in Figure 1. Consistent with the design, these are also introduced as changes.

Firm fixed effects panel data regressions are estimated. This approach controls for unobserved time-constant firm heterogeneity, a key aspect in the presence of unobserved firm fixed effects. Moreover, year dummies are included to control for potential endogeneity related to systematic shocks that lead to performance variations in all firms. The following general specification is assumed:

$\Delta$ Performance $\mathrm{e}_{k}^{t, t+1}=\alpha+\boldsymbol{\beta} \Delta \mathbf{Z}_{k}^{t-1, t}+\gamma$ Controls $+\eta_{k}+\psi^{t}+\varepsilon_{k}^{t}$,

where: $k=1, \ldots, K$ and $t=1, \ldots, T$ represent the cross-sectional units and the time periods, respectively; $\eta_{k}$ is a firm-specific effect, $\psi^{t}$ is the time-specific effect and $\varepsilon_{k}^{t}$ is an idiosyncratic error term. The dependent variables are changes in different firm performance measures between periods $t$ and $t+1$. These are, sequentially, the Luenberber indicator, efficiency change (EC), frontier change (FC) and some traditional accounting profitability ratios (e.g. changes in ROA (return on assets defined as net income divided by total assets) or net margin (defined as net income before preferred dividends divided by net revenues). The independent variables enter the model through the vector $\mathbf{Z}_{\mathbf{k}}$ that captures lagged changes (between $t-1$ and $t$ ) in organizational knowledge expenditures (R\&D) and stocks (intangible assets) thought to explain the dependent variables through the estimated parameters $\boldsymbol{\beta}$. In addition, the natural logarithm of total assets (a proxy of firm size) and the leverage ratio 
(defined as the ratio of the sum of the long-term and short-term debt to total assets) are introduced as firm specific controls. ${ }^{11}$

\subsection{Variables and data}

The managerial accounting design for benchmarking is completed by the variables’ definition and data. A profit maximizing approach, such as the one advocated for in this study's motivation and methodology can be defined using flow variables from income statements (see Kaplan and Atkinson (2000) for process costing definitions of operating profit). Moreover, using accounting data is helpful for benchmarking tasks that require information on industry peers to construct the best practice frontier.

Accounting definitions converge on the fact that generating revenues is a main goal of the firm. Accordingly, revenues can be used as the sole output variable given that they represent the primary source of earnings and cash flows associated with operating activities (Verma 1993; Thore et al. 1994; Demerjian et al. 2012; Baik et al. 2013). The employed input variables are consistent with the ones used by Thore et al. (1994), Demerjian et al. (2012) or Baik et al. (2013). The difference is that — for the main analysis — this study limits itself to flow variables and does not employ stocks. The rationale is that, apart from acknowledging the different natures of flows and stocks, mixing the two types would change the interpretation of the results. Flow variables provide a shorter term view of profitability, more appropriate for management control and reward systems. Indeed, for yardstick measures to be effective (see, e.g., Agrell et al. 2002; Bogetoft and Otto 2011) the variables for the analysis should be within the discretion of managers on the shorter term. This is for instance the case of inputs defined as flows as opposed to stocks (i.e. firm assets), which can only be

\footnotetext{
${ }^{11}$ For robustness, random effects and OLS regressions are also estimated. Additionally, standard errors are clustered at firm, and firm and year levels. Robustness tests and sensitivity checks are discussed in detail in Section 5.4 .
} 
modified in the long run or on some occasions are outside the discretion of managers (see, e.g., Kaplan and Atkinson 2000).

Profit is given by: $\pi=$ revenues - operating expenses. For a manufacturing firm, these operating expenses are: (i) cost of goods sold (COGS), (ii) selling, general and administrative expenses, and (iii) depreciation and amortization. These variables represent costs that are to a large extent within managerial discretion and are therefore suitable for the research design. When simultaneously_-but as different variables, not aggregated—introduced in the analysis, they reveal various firm configurations. It is therefore appropriate to use the proportional distance function (equation (2)) that sets the direction to the frontier following each firm's endogenous configuration and identifies frontier targets based on different inputs’ combinations. These resource mixes may change due to shifts in routines, knowledge, the environment or the judgment of the decision maker.

For instance, a high proportion of COGS illustrates that important resources are dedicated to direct manufacturing costs of material and labor. Alternatively, large values of the second input show that significant funds are not directly attributable to the production process but related to selling, general and administrative functions. These include marketing, employee benefits, commissions, advertising, promotion, and, more importantly, R\&D spending. Lastly, the approach is completed by the depreciation and amortization that capture the cost of depreciable assets and the cost allocation of intangible assets such as patents and trademarks. Intangible assets are yet another key component of our study as, jointly with R\&D spending, they proxy organizational knowledge.

Sensitivity checks draw from the definitions of Demerjian et al. (2012) and Baik et al. (2013) and introduce fixed inputs. Instead of expanding output while contracting all inputs, revenues are expanded and variable inputs (flows) are contracted, given some fixed inputs (stocks). Fixed inputs represent firm capacity, which is not included in managerial discretion. 
In this case, a profit definition is characterized by: $\pi=$ revenues - operating expenses, subject to firm capacity. Sensitivity checks follow equation (A1) in the Appendix, which introduces the proportional distance function with variable and fixed inputs. Variable inputs are the defined flows, whereas fixed inputs are fixed assets and number of employees. Moreover, to ensure that no double counting problems appear in the sensitivity checks, when introducing fixed assets as a fixed input, depreciation and amortization (the cost of assets) are not included as an input. Also, when introducing the number of employees, the sensitivity checks do not consider the cost of goods sold (which include the cost of direct materials but also of direct labor) and the selling, general and administrative expenses (which include wages corresponding to indirect labor).

A suitable sample for the analysis is a fast-moving industry well integrated in the growing knowledge economy that requires continuous investments in organizational routines (Foss 2005). High-technology industries include these characteristics jointly with business models that lead to accumulation of organizational knowledge and assets (see, e.g., Casadesus-Masanell and Ricart 2011). Consequently, the research design is applied to a panel of the U.S. technology hardware and equipment industry during 2000-2011. Thus, even if the interpretations follow yearly yardstick rationales, effects are shown inter-temporally over an extended twelve-years panel. Data come from Worldscope and the total number of observations (2,568 firm-year) is obtained after removing all units with missing values for inputs or output variables and checking for the presence of outliers. ${ }^{12}$

\section{[Table 1 about here]}

Table 1 presents the median values for the output (column (1)), input variables considered for the main specification (columns (2) to (4)), inputs used for sensitivity checks

\footnotetext{
${ }^{12}$ Tests for potential outliers were run based on Andersen and Petersen’s (1993) super-efficiency coefficient and Wilson (1993). The super-efficiency estimations indicate potentially influential units in the sample, which are sequentially removed and the efficiency measures re-estimated. Following Prior and Surroca (2010), this procedure is repeated as long as the null hypotheses of equality between efficiency scores cannot be rejected.
} 
(columns (5) to (7)), and R\&D and intangible assets (columns (8) and (9), respectively, which capture the two organization knowledge proxies). Also, complete accounting definitions of all variables are presented in the note of Table 1. Increases appear in all inputs and the output variable throughout the period. Exceptions are the lower values for the two recession periods of the U.S. economy, 2002-2003 and 2008-2009. As expected due to the industry type, COGS have the highest weight among the inputs (amounting to 61\% of total inputs in 2011, with a COGS/revenues ratio of 55\%). Furthermore, median R\&D spending and intangibles increased during 2001-2011 by 26\% and 39\%, respectively.

\section{RESULTS}

\subsection{Benchmarking indicators and accounting performance}

The test of equality of distributions between VRS and CRS inefficiency scores supports that assuming VRS better represents firm performances. Following Bogetoft and Otto (2011: 160-162), the inefficiency scores from the smaller technology (i.e. VRS is a more restrictive technology) are reported and interpreted. The Kolmogorov-Smirnov equality of distributions test reveals a significant difference at 1\% (p-value of 0.000) between VRS and CRS inefficiency scores. In addition, the scores obtained from the VRS proportional distance function are also significantly different at $1 \%$ (Kolmogorov-Smirnov p-value of 0.000 ) from the results of the more traditional output oriented distance function (i.e. maximizing revenues while holding inputs fixed). Taken together, these results corroborate that using a VRS proportional distance function is not only theoretically more suitable for managerial interpretations, but also that in this specific case it makes a difference for the interpretation of the results. $^{13}$

\footnotetext{
${ }^{13}$ The same results are obtained (significant differences at 1\%) if the Wilcoxon signed rank test is employed instead of the Kolmogorov-Smirnov equality of distributions test.
} 
Overall industry results for the benchmarking and accounting measures are illustrated in Figures 3 and 4, and Table 2. Static results show that median inefficiencies are generally below 0.2 (for all years except 2001), whereas most median ROA and net margin have the lowest values in 2009. These performance deteriorations may well be related to the two wellknown recession periods for the U.S. economy. These periods are 2002-2003 and the recent financial crisis that occurred in 2007-2008 and is still ongoing in various industries. Actually, one would expect a slow growth after 2009 to make up for the falling behind previously experienced.

[Figures 3 and 4, and Table 2 about here]

Yearly outcomes are in line with the above conjecture, as low performance mostly coincides with the economic downfalls. Static results (Figure 4 and Table 2) show that the first recession period is anticipated by rather high median inefficiency (0.21) in 2001, which drops to 0.14 and then increases to about 0.18 at the end of the analyzed period. The accounting ratios have similar evolutions, with negative median values for 2001-2003 and 2009 (excepting the zero figure for the operating margin in 2003). Two of the most relevant profitability measures, ROA and net margin, have the lowest median values in 2002 (-0.06 and -0.10 , respectively) and 2009 (-0.02 and -0.03, respectively). Conversely, in 2010 and 2011 these ratios report the best median levels (roughly 0.05) indicating the industry’s revival.

Dynamic benchmarking results are described in Figure 5 and Table 3 and offer interpretations in competitive settings. Note in Table 3 that the infeasible results amount to only $0.2 \%$ of the total sample (5 out of 2354) and thus are not expected to influence the overall interpretations. In Figure 3 the solid line is the sum of the dashed and dotted lines, while all positive/negative results show improvement/deterioration. The overall component (solid line in Figure 5 and Panel A of Table 3) computes $t$ to $t+1$ productivity changes relative to the frontier in $t$. The efficiency change (dashed line in Figure 5 and Panel B of Table 3) 
captures catching up or falling behind effects by calculating the difference in distances from the firm in $t$ and $t+1$ to the corresponding frontiers. The dotted line in Figure 5 (also Panel C of Table 3) shows the frontier shift between $t$ and $t+1$ (with the firm $t+1$ ), thus revealing the progress/regress of firms with similar configurations.

[Figure 5 and Table 3 about here]

The two economic distress periods are illustrated best by the saliently negative frontier shifts (dotted line in Figure 5), even if accompanied by positive efficiency change (dashed line in Figure 5). Simultaneous negative frontier shifts and positive efficiency changes indicate that firms at median level are closer to the frontier in 2002 and 2009 (than they were to the frontier in 2001 and 2008, respectively). In 2002 and 2009 the industry frontier has regressed, meaning that the frontier shifted closer to the firms, and not the firms to the frontier. The industry revival is revealed by the boost in the Luenberger indicator (which benchmarks firms' evolution to the frontier in $t$ ), driven mostly by the positive frontier shift during 2009-2010. Interestingly, the negative efficiency change median levels show that less than $50 \%$ of the firms progressed and a lot less pushed the frontier. Said otherwise, the distances among better and worse organizational results increased in 2009-2010 and remained stable during 2010-2011 (see zero values for all components).

[Figure 6 and Table 4 about here]

The changes in accounting ratios corroborate the benchmarking results (Figure 6 and Table 4), but provide limited strategic management interpretations. As in the static cases, results illustrate the same paths for all measures, and thus Table 4 focuses on two main profitability ratios, ROA and net margin. Although these ratios do not have benchmarking interpretations, their overall evolution during the analyzed time span is similar to the Luenberger indicator. ROA and net margin have their lowest values in 2000-2001, 
anticipating the industry recession, while the performance boosts and ensuing "zero changes" are consistent with previous interpretations.

\subsection{Organizational interpretations and firm-level strategic benchmarking}

From an organizational viewpoint, one could argue that knowledge accumulation occurs throughout the period, with highpoints when all benchmarking components show positive changes. This is less meaningful at industry level, where it is obvious for best performers (see Q3 results in Table 3). Organizational progress and knowledge accumulation interpretations are very important at firm level, as progress may arise not only via investments but also from recombining existing resources in novel ways (Denrell et al. 2003; Foss and Ishikawa 2007).

This process could be triggered by changes in resources or the environment. In the absence of shocks or in situations of homogenous effects on the industry, the observed results' fluctuations may actually reflect shifts in organizational knowledge or —in broad terms—in managerial decision making. Indeed, the benchmarking indicators suggest that all positive changes during multiple subsequent periods are probably linked not only to increased accounting performance but also to organizational routines' enhancements. According to strategy and managerial accounting viewpoints, paying bonuses can be tied to positive results in both the Luenberger indicator and efficiency change (catching up effect). In this sense, the management control system would capture changes with respect to stable but also moving yardsticks (see, e.g., Agrell et al. 2002; Bogetoft and Otto 2011). This, at median level, occurs between 2005 and 2006.

[Figure 7 about here]

Given the obvious importance of firm-level analyses, Figure 7 presents a real and meaningful unit-to-unit benchmarking scenario as proposed through equations (6) and (7). Two leading firms from the semiconductor sector are compared: Micron Technology (MT, the analyzed firm) and Texas Instruments (TI, the benchmark). In Panel A of Figure 7 one can 
follow the first benchmarking component of equation (6). At the zero level, the inefficiency levels of the two firms are equal. Positive/negative results show that MT is better/worse than TI in the corresponding year. Note, for instance, that TI is performing better than MT around the two crisis periods, whereas MT manages to reduce the gap after the economic downturns.

Panel B of Figure 7 enhances these static interpretations by illustrating the two firms competing in a dynamic environment (see equation (7)). The left figure shows the analyzed firm's efficiency change between $t$ and $t+1$ (solid line). MT improves its performance shortly after the crisis episodes. Interestingly, MT's performance in $t+1$ converges to the benchmark's (TI) performance in $t$ at the end of the period on the declining trend in MT's results (dashed line). The figure on the right in Panel B provides a mirrored image, in which MT is the benchmark in $t$ and TI is the analyzed firm in $t+1$. Dynamic unit-to-unit analyses are realistic as managers fix targets (i.e. benchmark in $t$ ) for control and reward systems in the next period (analyzed firm in $t+1$ ).

\subsection{Knowledge investments and performance feedback}

Second stage analyses estimate regressions that sequentially introduce the three benchmarking measures and the main accounting profitability ratios (ROA and net margin) as dependent variables. Similarly to the first stage analysis, different performance measures lead to complementary strategic interpretations. Table 5 presents the results for each specification. The organizational knowledge proxies linked to the feedback process and thought to explain performance movements are the lagged changes in R\&D spending and intangible assets. These variables capture flows (R\&D spending, which has a shorter term interpretation) and stock accumulations (intangible assets, which have a longer term value, especially in hightechnology industries) (see, e.g., Casadesus-Masanell and Ricart 2011). All specifications include firm and year effects and control for size and debt levels (liabilities (sum of the longterm and short-term debt) divided by total assets). 


\section{[Table 5 about here]}

Organizational knowledge accumulation proxied through changes in intangibles is positively associated with the Luenberger indicator (see the significant parameter estimate for the intangibles' change in Table 5, specification (1)). It may well be that no significant estimate is found for changes in R\&D spending because, even if these foster innovations, their relationship to the frontier benchmarking measure is only shown via stocks instead of flows (see similar interpretations in Acs et al. (2009)). Furthermore, outcomes for the frontier $t$ benchmarking (the Luenberger indicator) suggest that intangibles may be imitable and incumbents’ observed results could be matched via catching up processes involving organizational knowledge investments (Knott et al. 2003).

On a related note, Knott (2003) and Knott and Posen (2009) argue that firms use R\&D spending to regain eroded competitive advantages. When the dependent variable is efficiency change, which accounts for movements in both the firm and the frontier (specification (2) in Table 5), there is no significant result for the change in intangibles. The efficiency change benchmarking measure is negatively related to $R \& D$ spending changes. This indicates that enhancing $R \& D$ spending is related to a falling behind effect, probably because this cost could be negatively related to immediate firm outcomes. Conversely, changes in R\&D spending are significantly and positively associated with frontier shifts (specification (3) in Table 5). That is, enhancements in practices of firms with similar configurations that push the frontier are positively associated with R\&D spending increases.

On the one hand, the positive relationship between frontier shifts and changes in R\&D is in line with the negative link between efficiency change and changes $R \& D$ (a falling behind effect), and also consistent with the first stage analysis' interpretations. That is, it is expected that in the presence of industry progress (positive frontier shifts) there may be an immediate cost for the firms that are not pushing the frontier or simply not improving their outcomes, 
followed on most occasions by an adjustment period. Another facet of this result could come from the firms' strategic behavior, as instead of straightforward catching up to the current period frontier, investments in $R \& D$ could be driven by strategic renewal, which generally has effects on the longer term not captured well by the used measures (Knott and Posen 2009). For these effects to be revealed, one would need to shift focus from industry benchmarking to internal measures for business model implementation (see, e.g., Brea-Solís et al. 2015).

On the other hand, the positive links of R\&D changes to frontier shifts and accounting profitability ratios (specifications (2) to (5) in Table 5) corroborate the results from studies that identify R\&D flows as a useful explanatory variable of the firms’ production outcomes. When changes in accounting ratios are the dependent variables (specifications (4) and (5) in Table 5), the results support the usual economics intuition that strong correlations exist between R\&D spending and profitability (Capon et al. 1990; Griliches 1998; O’Mahony and Vecchi 2009). Nevertheless, these links between changes in accounting ratios and organizational investments should be taken with a grain of salt, as their interpretations may be less precise than in the case of the benchmarking measures. For instance, ROA includes various types of assets and extraordinary results, while the net margin comprises the impact of taxes. Thus, these ratios’ construction affects their interpretation accuracy, and, for example, may lead to the negative parameter estimate (although weakly significant) for the relation between changes in intangibles and the net margin, possibly an immediate cost similar to the one in specification (2).

\subsection{Sensitivity checks and robustness analyses}

In a managerial accounting fashion, a series of sensitivity checks are run considering fixed and variable inputs for the benchmarking measures. As indicated in the variables’ description, these specifications mix managerial discretion over flows with firm capacity given by fixed inputs that can be only modified on the longer term and on many occasions are 
not within to managerial discretion. Results are obtained following equations (A1) and (A2) and are illustrated in Figure A1, all in the Appendix. ${ }^{14}$ Note that for the two additional inputsoutput specifications the tenor of the benchmarking results does not change. Nevertheless, when employed in the second stage, the significance of the regression results—although still maintaining the same interpretations - is weaker when less managerial discretion is allowed. Indeed, the research design its implications are most meaningful for analyses that establish benchmarks in terms of variables that fall within shorter term managerial discretion.

Second stage analyses undergo a broad series of robustness tests. All specifications are estimated following the fixed effects regression model in equation (8), random effects and OLS regressions, clustering by firm, and firm and year when calculating the robust standard errors. Moreover, the explanatory variables are also introduced individually in regressions. In all alternative specifications, results do not change their tenor. Another specific concern for the reliability of the second stage results was the relatively high number of zero values reported for $\mathrm{R} \& \mathrm{D}$ spending and intangibles. These differ from missing values that were treated as such when estimating the regression in Table 5. All regressions are rerun after transforming the zero values for R\&D spending and intangibles into missing values. Results’ interpretations are maintained, as parameter estimates preserve their signs and significance levels.

\section{CONCLUDING REMARKS}

This study proposes a managerial accounting design with performance feedback that operationalizes decision making based on resources and routines. In doing so, it bridges a gap between studies on firm productivity based on frontier techniques and strategic management.

\footnotetext{
${ }^{14}$ See the various inputs-output specifications for sensitivity checks in the description of Figure (A1). Sensitivity checks also consider including R\&D spending as an individual input. Results do not change significantly. Results do not change their tenor if R\&D spending and intangibles are only employed in the second stagewhile R\&D spending is removed from the inputs side of the benchmarking measure-however, this inputs' specification would be flawed as it does not respect the firms' profit function.
} 
The research design integrates the endogenous components of across-firms heterogeneous routines that are fundamental for firm performance (Winter 2003; Abell et al. 2008; Felin and Foss 2011; Argyres et al. 2012). It does so by applying frontier benchmarking rationales based on managerial accounting feedback and reveals how changes in firm results are linked to shifts in organizational knowledge investments. This paper has implications for organizational control and reward systems (see, e.g., Ittner and Larcker 1997; Kaplan and Atkinson 2000; Balk 2003; Langfield-Smith 2005; Smith 2005). These contributions are closely linked to using frontier benchmarking to elicit information for incentive plans and yardstick compensation measures (see, e.g., Agrell et al. 2002; Bogetoft and Otto 2011). As a practical implication, the paper proposes new indicators for firm-level strategic benchmarking, which can be more appealing to decision makers than industry-level schemes.

The empirical application demonstrates the usefulness of the proposed design for management and accounting theory, and for researchers and managers who design profitability analyses. This study can be used for instituting control and reward systems based on benchmarking measures that isolate changes in firm outcomes with respect to the industry frontier in a certain year, catching up or falling behind effects, and frontier shifts.

Results for twelve-years panel of the U.S. technology hardware and equipment industry show negative frontier shifts during times of economic distress. Around 2001 and 2008 the frontier pressed down on the firms, instead of receiving the usual push from the best performers. This push appears in 2009-2010, indicating industry revival. By jointly interpreting frontier shifts with catching up or falling behind effects, one observes that less than $50 \%$ of the firms progressed and a lot less contributed to pushing the frontier. In strategic management terms, this implies that the distance between best and worse performers increased and bigger distances exist between firms in 2009-2011 than before the 2008 crisis. 
Frequent positive changes in benchmarking measures are indicative not only of increased accounting performance but also of organizational knowledge enhancements. These organizational progress interpretations are meaningful at firm level as they can be the basis of control and reward systems. For instance, paying bonuses can be tied to positive results in both the Luenberger indicator and efficiency change (catching up effect). In this case, the management control system would compare firm results with respect to a stable yardstick but also to the moving industry frontier (see, e.g., Agrell et al. 2002; Bogetoft and Otto 2011). At top quartiles this can be observed for various periods, whereas at median level it occurs during 2005-2006.

Second stage analyses corroborate the organizational knowledge accumulation viewpoint, as enhancements in intangibles are positively related to changes in the Luenberger indicator. This could indicate that intangibles are imitable and incumbents' results can be matched through catching up processes generated via knowledge investments (Knott et al. 2003). Also, R\&D changes are positively related to frontier shifts and negatively to efficiency change. This may suggest that increasing R\&D spending can have an immediate cost observed for firms that are neither pushing the frontier nor progressing. R\&D spending, however, could also be aimed at longer term strategic renewal and regaining eroded competitive advantages (Knott and Posen 2009). Overall, the results support the documented strong relationship between R\&D and firm performance (Capon et al. 1990; Griliches 1998; O’Mahony and Vecchi 2009).

Future research could scrutinize whether the relationship between investments in organizational knowledge and firm outcomes is different depending on ex ante performance levels. At a first glance, the descriptive results do not support this conjecture given that changes in benchmarking measures and accounting ratios have similar evolutions at Q1, median and Q3 levels. These results and existing theoretical models could be used as a base 
for developing normative approaches to optimal levels of knowledge investments. Whereas this study does not assume that either positive or negative changes in knowledge investments are desired, future studies could use network DEA (Färe et al. 2007) to treat knowledge investments as an intermediate product that is maximized or minimized according to the normative objectives. This approach could be integrated into the business model rationales of Casadesus-Masanell and Ricart (2011), who refer to network effects in virtuous circles that enhance competitive advantages, or of Brea-Solís et al. (2015), who show that profit consequences are mainly driven by implementation (i.e. micro-level decision making). Future work could also implement the proposal of Daraio and Simar (2014) to link optimal knowledge investments with benchmarking measures based on directional vectors that account for exogenous contextual factors. Yet another important line of research is to scrutinize whether the few efforts to operationalize routines and their link to firm performance might converge to similar conclusions. This work and the Bayesian approach of Denrell et al. (2013) could serve as starting points.

\section{ACKNOWLEDGEMENTS}

I thank two anonymous referees, participants at the European Workshop on Efficiency and Productivity Analysis in Helsinki, the European Accounting Association conference in Paris, the Strategic Management Society conference in Copenhagen, and the Barcelona Accounting Seminar at ESADE for useful comments. This research received financial support from the Spanish Ministry of the Economy and Competitiveness through grant ECO201457131-R. Usual disclaimers apply.

\section{REFERENCES}

Abell, P., Felin, T., Foss, N., 2008. Building micro-foundations for the routines, capabilities, and performance links. Managerial and Decision Economics 29(6), 489-502.

Acs, Z.J., Braunerhjelm, P., Audretsch, D.B., Carlsson, B., 2009. The knowledge spillover theory of entrepreneurship. Small Business Economics 32(1), 15-30. 
Agrell, P.J., Bogetoft, P., Tind, J., 2002. Incentive plans for productive efficiency, innovation and learning. International Journal of Production Economics 78(1), 1-11.

Andersen, P., Petersen, N.C., 1993. A procedure for ranking efficient units in data envelopment analysis. Management Science 39(10), 1261-1264.

Antle, R., Bogetoft, P., Stark, A.W., 2001. Information systems, incentives and the timing of investments. Journal of Accounting and Public Policy 20(4-5), 267-294.

Aparicio, J., Pastor, J.T., Zofio, J.L., 2013. On the inconsistency of the MalmquistLuenberger index. European Journal of Operational Research 229(3), 738-742.

Argyres, N.S., Felin, T., Foss, N., Zenger, T., 2012. Organizational economics of capability and heterogeneity. Organization Science 23(5), 1213-1226.

Augier, M., Teece, D.J., 2007. Dynamic capabilities and multinational enterprises: Penrosen insights and omissions. Management International Review 47(2), 175-192.

Baik, B., Chae, J., Choi, S., Farber, D.B., 2013. Changes in operational efficiency and firm performance: A frontier analysis approach. Contemporary Accounting Research 30(3), 996-1026.

Balk, B.M., 2003. The residual: On monitoring and benchmarking firms, industries, and economies with respect to productivity. Journal of Productivity Analysis 20(1), 5-47.

Banker, R.D., Chang, H., Majumdar, S.K., 1996. A framework for analyzing changes in strategic performance. Strategic Management Journal 17(9), 693-712.

Banker, R.D., Chang, H., Natarajan, R., 2007. Estimating DEA technical and allocative inefficiency using aggregate cost or revenue data. Journal of Productivity Analysis 27(2), 115-121.

Barney, J.B., 1991. Firm resources and sustained competitive advantage. Journal of Management 17(1), 99-120.

Blundell R., Griffith R., Van Reenen, J., 1999. Market share, market value and innovation in a panel of British manufacturing firms. Review of Economic Studies 66, 529-554.

Bogetoft P., Olesen, H.B., 2003. Incentives, information systems, and competition. American Journal of Agricultural Economics 85(1), 234-247.

Bogetoft P., Otto, L., 2011. Benchmarking with DEA, SFA and R. Springer, New York.

Boussemart, J.-P., Briec, W., Kerstens, K., Poutineau, J.-C., 2003. Luenberger and Malmquist productivity indices: Theoretical comparisons and empirical illustration. Bulletin of Economic Research 55(4), 391-405.

Brea-Solís, H., Casadesus-Masanell, R., Grifell-Tatjé, E., 2015. Business model evaluation: Quantifying Walmart's sources of advantage. Strategic Entrepreneurship Journal 9(1), 12-33.

Briec, W., 1997. A graph type extension of Farrell technical efficiency measure. Journal of Productivity Analysis 8(1), 95-110.

Briec W., Kerstens K. 2009a. Infeasibility and directional distance functions with application to the determinateness of the Luenberger productivity indicator. Journal of Optimization Theory and Applications 141(1), 55-73.

Briec W., Kerstens K. 2009b. The Luenberger productivity indicator: An economic specification leading to infeasibilities. Economic Modelling 25(3), 597-600.

Bromiley, P., Miller, K.D., Rau. D., 2001. Risk in strategic management research. In Hitt, M.A., Freeman, R.E. Harrison, J.S. (eds.), The Blackwell Handbook of Strategic Management 259-288. Oxford: Blackwell.

Camp, R.C., 1995. Business Process Benchmarking: Finding and Implementing Best Practices. ASQC Quality Press.

Camp, R.C., 1998. Best practice benchmarking: the path to excellence. CMA Magazine 72(8), 10-5. 
Capon, N., Farley, U.J., Hoenig S., 1990. Determinants of financial performance: A metaanalysis. Management Science 36(10), 1143-1159.

Casadesus-Masanell, R., Ricart, J.E., 2011. How to design a winning business model. Harvard Business Review 89(1-2), 100-107.

Chambers, R.G., Chung Y., Fare, R., 1998. Profit, directional distance functions, and Nerlovian efficiency. Journal of Optimization Theory and Applications 98(2), 351-364.

Chambers, R.G., Färe, R., Grosskopf, S., 1996. Productivity growth in APEC countries. Pacific Economic Review 1(3), 181-190.

Chambers, R.G., Pope, R.D., 1996. Aggregate productivity measures. American Journal of Agricultural Economics 78(5), 1360-1365.

Coleman, J.S., 1990. Foundations of Social Theory. Belknap Press, Cambridge, MA.

Daraio, C., Simar, L., 2014. Efficiency and benchmarking with directional distances. A data driven approach. Dipartamento de Ingegnieria Informatica, Technical Report no 7/2014.

Demerjian, P., Lev, B., McVay, S., 2011. Quantifying managerial ability: A new measure and validity tests. Management Science 58(7), 1229-1248.

Denrell, J., Fang, C., Winter, S.G., 2003. The economics of strategic opportunity. Strategic Management Journal 24(10), 977-990.

Denrell, J., Fang, C., Zhao, Z., 2013. Inferring superior capabilities from sustained superior performance: A Bayesian analysis. Strategic Management Journal 34(2), 182-196.

Dutta, S., Narasimhan, O., Rajiv, S., 1999. Success in high-technology markets: Is marketing capability critical? Marketing Science 18(4), 547-568.

Epure, M., Kerstens K., Prior, D., 2011. Technology-based total factor productivity and benchmarking: New proposals and an application. Omega - The International Journal of Management Science 39(6), 608-619.

Ettlie, J.E., 1998. R\&D and global manufacturing performance. Management Science 44(1), $1-11$.

Färe, R., Grosskopf, S., Lovell, C.A.K., 1994. Production Frontiers. Cambridge University Press, New York.

Färe. R., Grosskopf S., Whittaker, G., 2007. Network DEA. In Zhu J., and Cook W. (eds.), Modeling Data Irregularities and Structural Complexities in Data Envelopment Analysis, Springer.

Felin, T., Foss, N.J., 2011. The endogenous origins of experience, routines and organizational capabilities: The poverty of stimulus. Journal of Institutional Economics 7(2), 231-256.

Felin, T., Foss, N.J., Heimeriks, K.H., Madsen, T.L., 2012. Microfoundations of routines and capabilities: Individuals, processes, and structure. Journal of Management Studies 49(8), 1351-1374.

Foss, N.J., 2005. Strategy, Economic Organization, and the Knowledge Economy: The Coordination of Firms and Resources. Oxford University Press, New York.

Foss, N.J., Ishikawa, I., 2007. Towards a dynamic resource-based view: Insights from Austrian capital and entrepreneurship theory. Organization Studies 28(5), 749-772.

Foss, N.J., Stieglitz, N., 2011. Modern resource-based theory(ies). In Dietrich M., Krafft J. (eds.) Handbook of the Economics of the Firm, Edward Elgar, Cheltenham,

Greve, H.R., 2003. Organizational Learning from Performance Feedback: A Behavioral Perspective on Innovation and Change. Cambridge University Press, Cambridge.

Grifell-Tatjé, E., Lovell, C.A.K., 1999. Profits and productivity. Management Science 45(9), 1177-1193.

Griliches, Z.R., 1998. R\&D and productivity: The econometric evidence. The University of Chicago Press, Chicago.

Helfat, C.E., Peteraf, M.A., 2003. The dynamic resource-based view: Capability life cycles. Strategic Management Journal 24(10), 997-1010. 
Ittner, C.D, Larcker, D.F., 1997. Quality strategy, strategic control systems, and organizational performance. Accounting, Organizations and Society 22(3/4), 293-314.

Kaplan, R.S., Atkinson, A.A., 2000. Advanced Management Accounting. $3^{\text {th }}$ ed., Prentice Hall, Upper Saddle River.

Knott, A.M., 2003. Persistent heterogeneity and sustainable innovation. Strategic Management Journal 24(8), 687-705.

Knott, A.M., Bryce, D.J., Posen, H.E., 2003. On the strategic accumulation of intangible assets. Organization Science 14(2), 192-207.

Knott, A.M., Posen, H.E., 2009. Firm R\&D behavior and evolving technology in established industries. Organization Science 20(2), 352-367.

Langfield-Smith, K., 2005. What do we know about management control systems and strategy? in Chapman, C.S. (ed.) Controlling Strategy: Management, Accounting and Performance Measurement, Oxford University Press, Oxford.

Luenberger, D.G., 1992. Benefit functions and duality. Journal of Mathematical Economics 21(5), 461-481.

O’Mahony, M., Vecchi, M., 2009. R\&D, knowledge spillovers and company productivity performance. Research Policy 38(1), 35-44.

Penrose, E.T., 1959. The Theory of the Growth of the Firm. Wiley, New York.

Prior, D., Surroca, J., 2010. Performance measurement and achievable targets for public hospitals. Journal of Accounting, Auditing and Finance 25(4), 749-765.

Ray, S.C., 2004. Data Envelopment Analysis: Theory and Techniques for Economics and Operations Research. Cambridge University Press, New York.

Romer, P., 1990. Endogenous technological change. Journal of Political Economy 98(5), 71102.

Smith, M., 2005. Performance Measurement \& Management. Sage, London.

Teece, D.J., 2007. Explicating dynamic capabilities: The nature and microfoundations of (sustainable) enterprise performance. Strategic Management Journal 28(13), 1319-1350.

Teece, D.J., Pisano, G., Shuen, A., 1997. Dynamic capabilities and strategic management. Strategic Management Journal 18(7), 509-533.

Thore, S., Kozmetsky, G., Phillips, F., 1994. DEA of financial statements data: The U.S. computer industry. Journal of Productivity Analysis 5(3), 229-248.

Verma, K., 1993. Managerial efficiency: A study of management buyouts. Contemporary Accounting Research 10(1), 179-204.

Wernerfeldt, B., 1984. A resource based view of the firm. Strategic Management Journal 5(2), 171-180.

Wilson, P.W., 1993. Detecting outliers in deterministic nonparametric frontier models with multiple outputs. Journal of Business \& Economic Statistics 11(3), 319-323.

Winter, S.G., 2003. Understanding dynamic capabilities. Strategic Management Journal 24(10), 991-995.

Zofio, J.L., Pastor, J.T., Aparicio J., 2013. The directional profit efficiency measure: On why profit inefficiency is either technical or allocative. Journal of Productivity Analysis 40(3), 257-266.

Zollo, M., Winter, S.G., 2002. Deliberate learning and the evolution of dynamic capabilities. Organization Science 13(3), 339-351.

Zott, C., 2003. Dynamic capabilities and the emergence of intra-industry differential firm performance: Insights from a simulation study. Strategic Management Journal 24(2), 97125. 
Figure 1: Routines and feedback on organizational performance

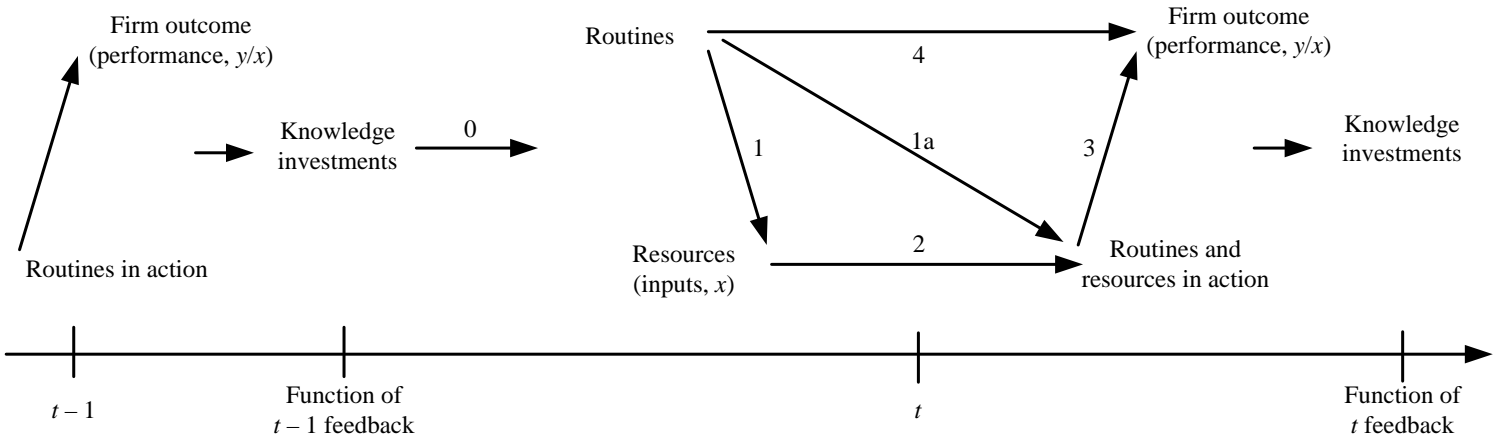

Figure 2: Disentangling the Luenberger indicator

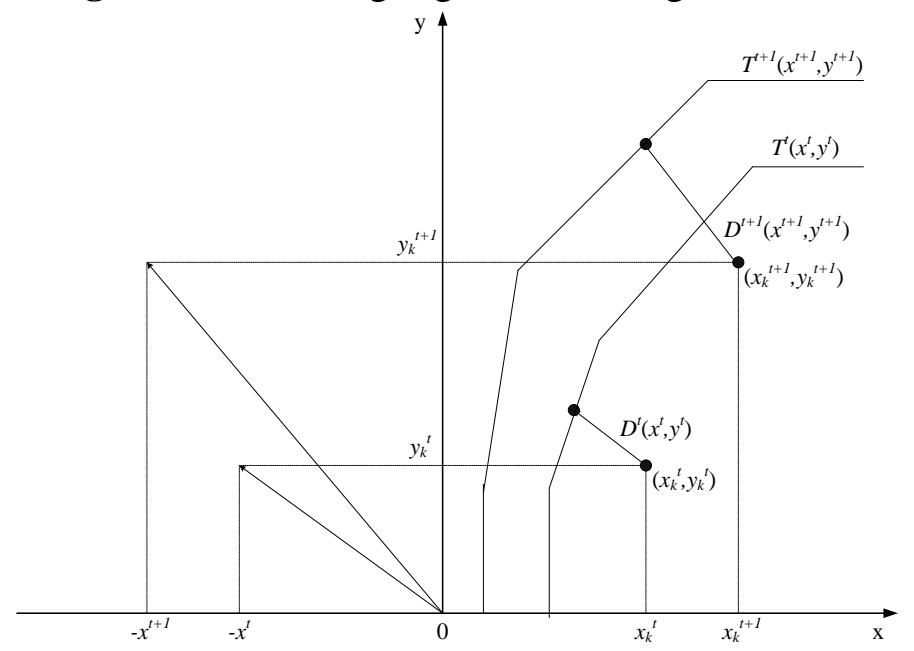


Figure 3: Histograms (in percent) for benchmarking measures
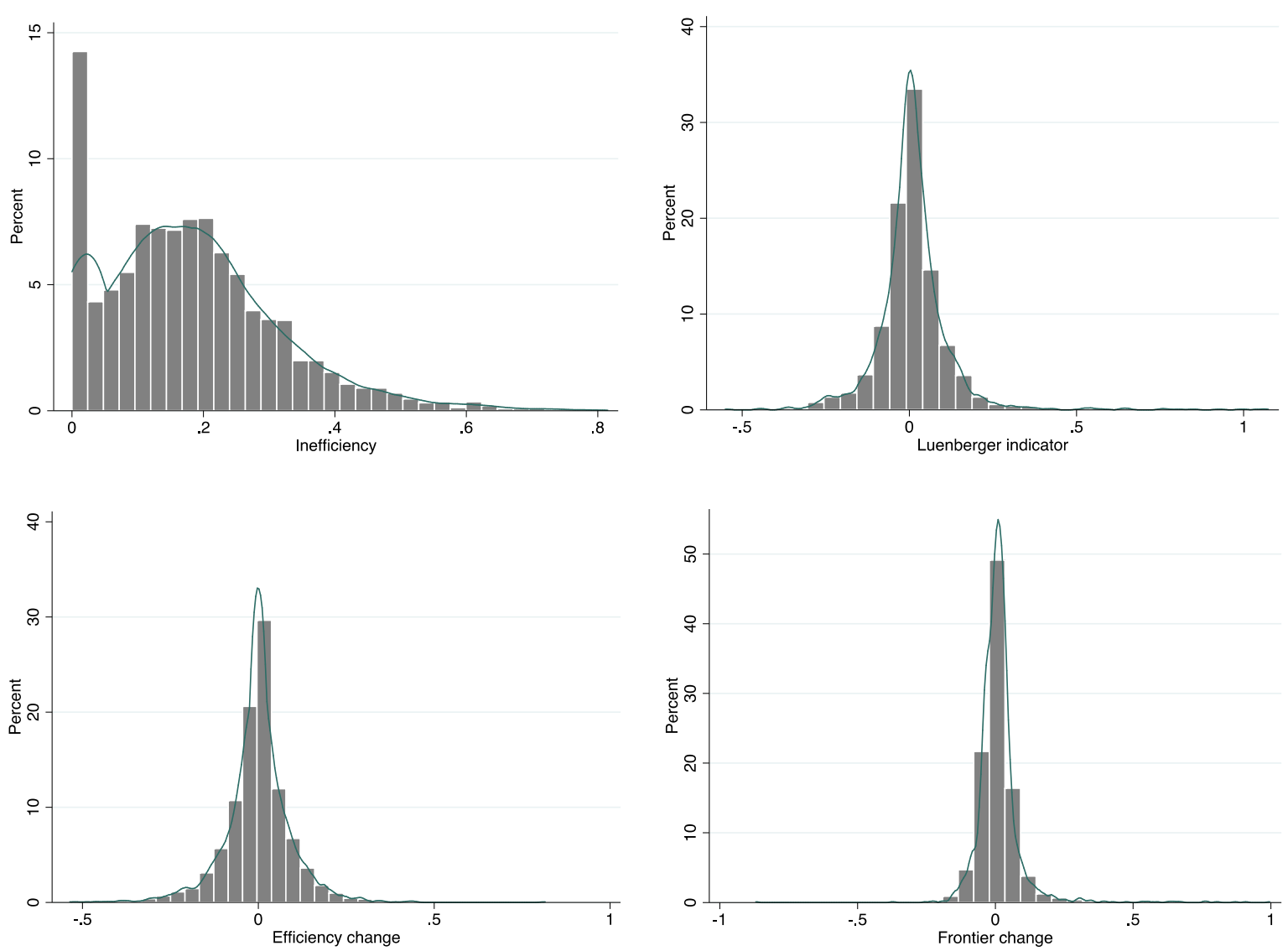

Histograms representing the percentage of firms with their corresponding benchmark performance measures during 2000-2011. Kernel (Epanechnikov) density estimates are added to the plots. Inefficiency scores (bin=34, width=.02398041) are computed according to equation (2) represent degrees of inefficiency; the lowest values are the best results. The Luenberger indicator (bin=33, width=.04923313), efficiency change (bin=33, width=.04095243) and frontier change (bin=33, width=.05652801) are computed following equations (4) and (5), and the distance function in equation (2). The inputs are (i) cost of goods sold (COGS), (ii) selling, general and administrative expenses, and (iii) depreciation and amortization, while the output is revenues. All inputs and the output are variable.

Figure 4: Static performance measures

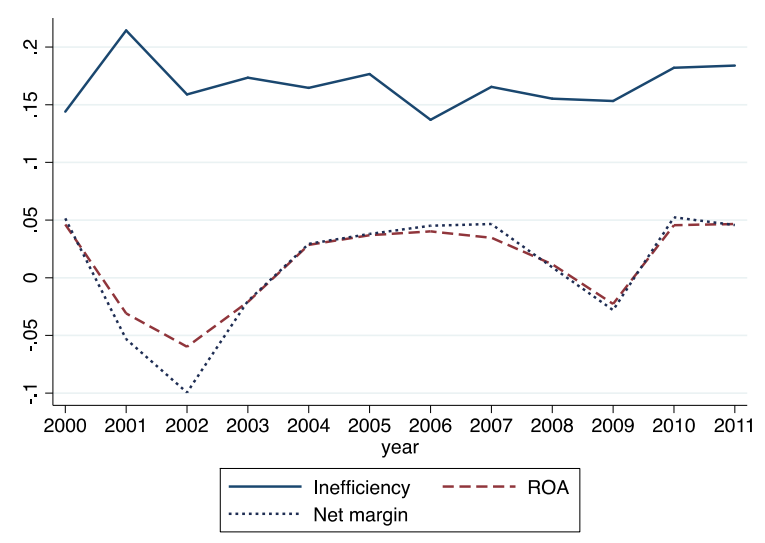

Median values. Inefficiency scores (solid line) are computed according to equation (2) represent degrees of inefficiency; the lowest values are the best results. The opposite is valid for ROA (return on assets defined as net income divided by total assets) and net margin (defined as net income before preferred dividends divided by net revenues) (dashed and dotted lines), which are interpreted in the traditional fashion: the higher the value, the better the performance. For the inefficiency measure, inputs are (i) cost of goods sold (COGS), (ii) selling, general and administrative expenses, and (iii) depreciation and amortization, while the output is revenues. All inputs and the output are variable. 


\section{Figure 5: Luenberger indicator decomposition}

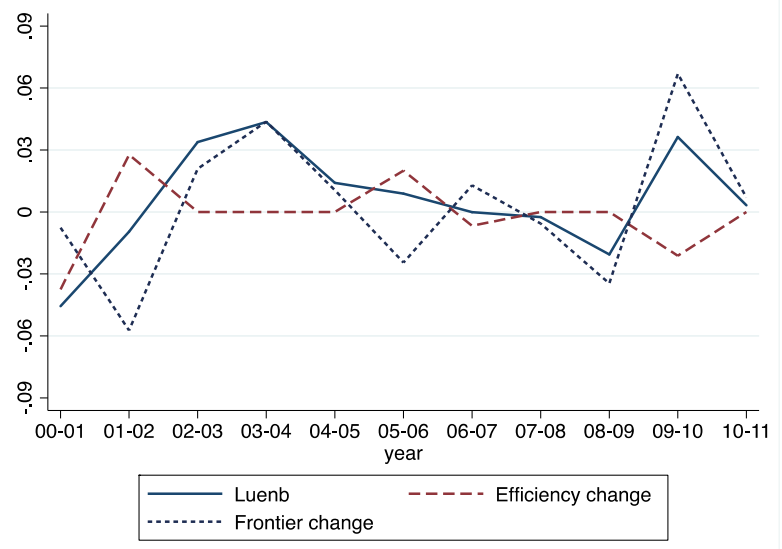

Indicators are computed following equations (4) and (5), and the distance function in equation (2). All values represent changes at median level between the periods indicated on the horizontal axis. Results of zero show no change; positive/negative results show improvement/deterioration. Inputs are (i) cost of goods sold (COGS), (ii) selling, general and administrative expenses, and (iii) depreciation and amortization, while the output is revenues. All inputs and the output are variable.

Figure 6: Accounting performance changes
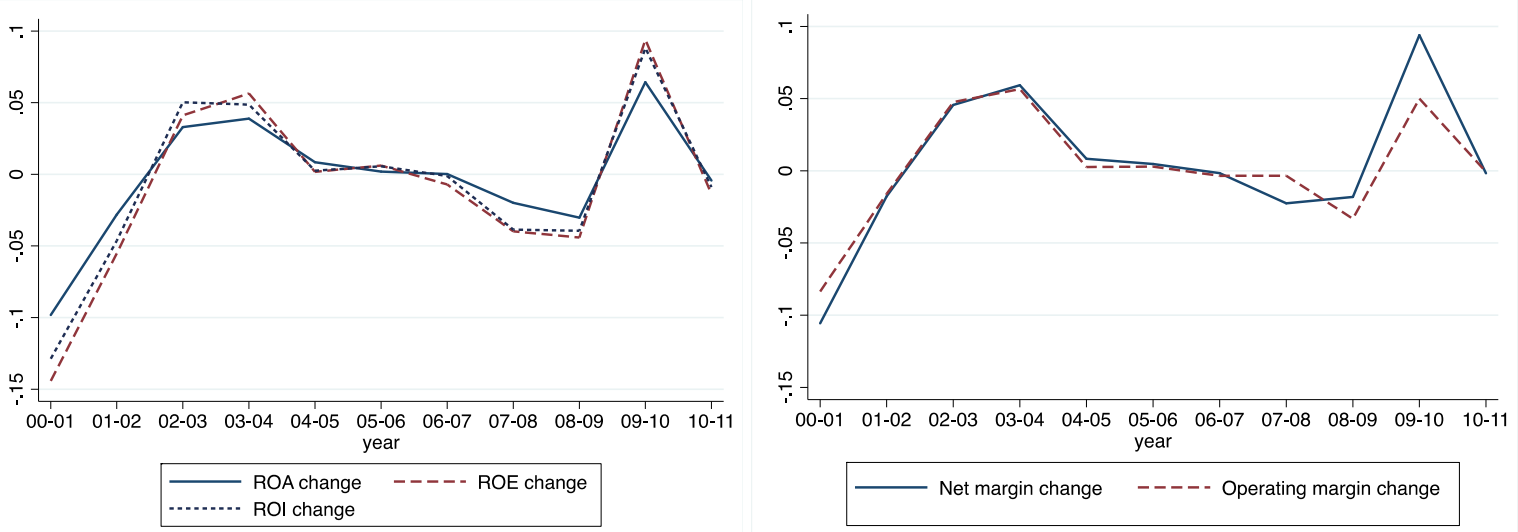

ROA (return on assets): net income divided by total assets; ROE (return on equity): net income divided by shareholders' equity; ROI (return on investment): profit from investment divided by cost of investment; Net margin: net income before preferred dividends divided by net revenues; Operating margin: operating income divided by net revenues. For all cases values represent changes at median level between the periods indicated on the horizontal axis. Results of zero show no change; positive/negative results show improvement/deterioration. 
Figure 7: Firm-level strategic benchmarking in the semiconductor sector: Micron Technology (analyzed firm) vs. Texas Instruments (benchmark)

\section{Panel A: Decomposition proposal 1 (equation (6))}

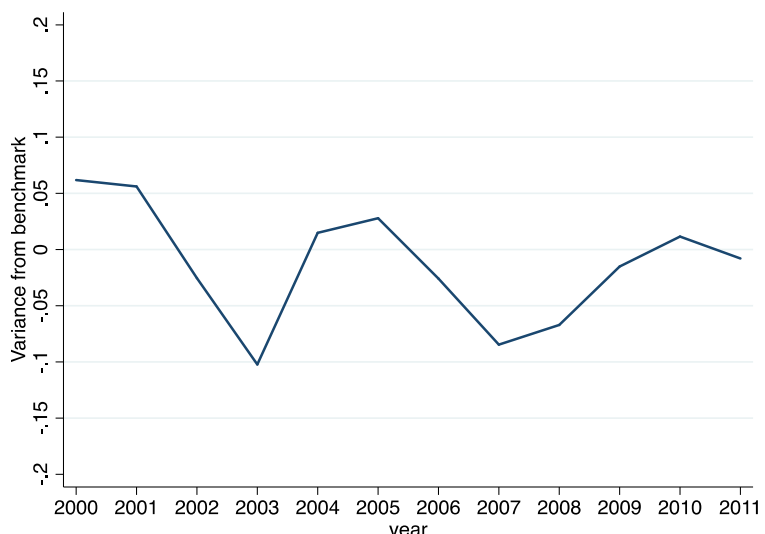

Results of zero in equation (6) show that the efficiency of Micron Technology is equal to the one of Texas Instruments in the corresponding year; positive/negative results show that Micron Technology is better/worse than Texas Instruments in the corresponding year. Inputs are (i) cost of goods sold (COGS), (ii) selling, general and administrative expenses, and (iii) depreciation and amortization, while the output is revenues. All inputs and the output are variable.

\section{Panel B: Decomposition proposal 2 (equation (7))}
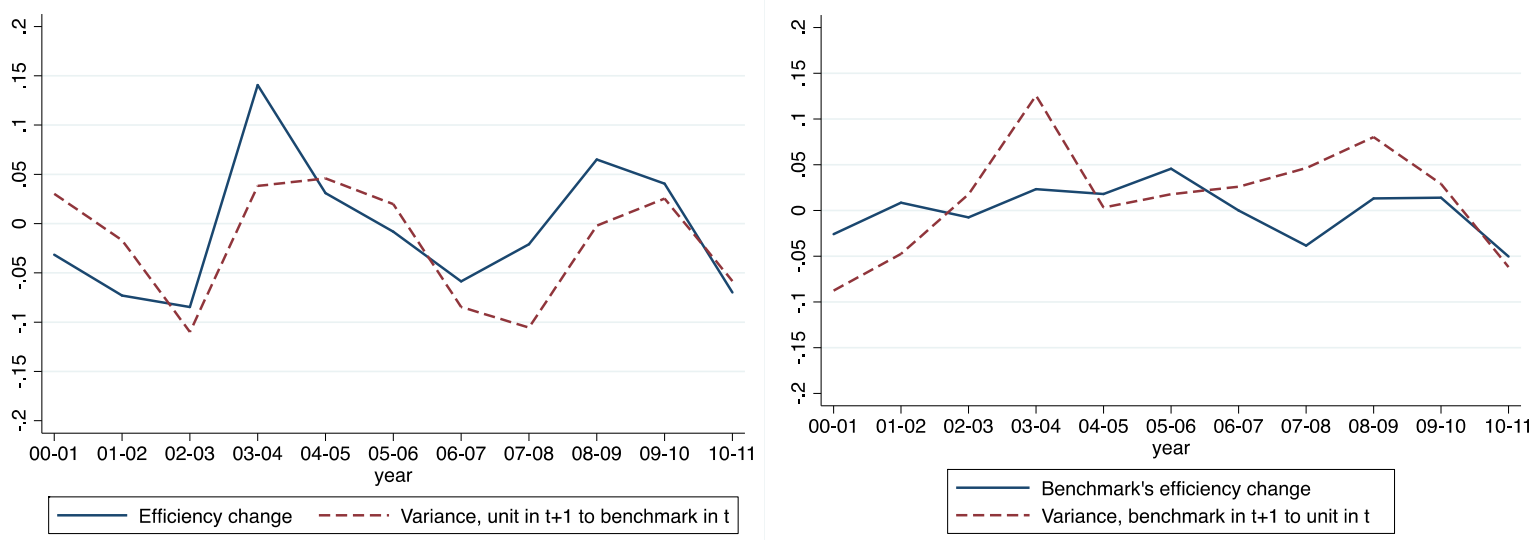

Left figure: first component of the decomposition (dashed line) and benchmarks efficiency change (last component of the decomposition, equation (7)). Results of zero show that the efficiency of Micron Technology in $t+1$ is equal to the one of Texas Instruments in $t$; positive/negative results show that Micron Technology in $t+1$ is better/worse than Texas Instruments in $t$. Right figure: second component of the decomposition (dashed line) and benchmarks efficiency change (last component of the decomposition, equation (7)). Results of zero show that the efficiency of Texas Instruments in $t+1$ is equal to the one of Micron Technology in $t$; positive/negative results show that Texas Instruments in $t+1$ is better/worse than Micron Technology in $t$. Inputs are (i) cost of goods sold (COGS), (ii) selling, general and administrative expenses, and (iii) depreciation and amortization, while the output is revenues. All inputs and the output are variable. 
Table 1: Variables considered in varisous analysis stages

\begin{tabular}{rrrrrrrrrr}
\hline \multicolumn{1}{r|r}{ Year Revenues } & COGS & $\begin{array}{r}\text { Sell \& } \\
\text { adm. }\end{array}$ & $\begin{array}{r}\text { Depr. \& Operating } \\
\text { amort. }\end{array}$ & $\begin{array}{r}\text { expenses } \\
\text { Empl. }\end{array}$ & $\begin{array}{r}\text { Fixed } \\
\text { assets }\end{array}$ & $\begin{array}{r}\text { R\&D } \\
\text { Intang. }\end{array}$ \\
\hline 2000 & 196,973 & 105,067 & 69,707 & $(4)$ & $(5)$ & $(6)$ & $(7)$ & $(8)$ & $(9)$ \\
2001 & 218,918 & 124,686 & 81,432 & 15,817 & 183,975 & 649 & 35,500 & 24,707 & 13,672 \\
2002 & 189,293 & 94,388 & 78,456 & 14,555 & 197,266 & 613 & 37,762 & 31,931 & 15,169 \\
2003 & 187,790 & 101,562 & 69,787 & 11,577 & 187,811 & 594 & 32,426 & 26,711 & 19,790 \\
2004 & 224,748 & 130,430 & 76,453 & 10,457 & 233,521 & 644 & 30,918 & 27,019 & 22,633 \\
2005 & 268,196 & 138,405 & 87,249 & 11,256 & 255,764 & 715 & 29,763 & 29,532 & 25,281 \\
2006 & 289,646 & 158,932 & 93,518 & 10,449 & 279,646 & 775 & 30,532 & 31,022 & 33,744 \\
2007 & 284,965 & 163,365 & 97,244 & 11,090 & 271,140 & 791 & 29,999 & 36,283 & 37,113 \\
2008 & 283,244 & 156,026 & 104,092 & 11,288 & 298,577 & 828 & 29,697 & 39,250 & 32,967 \\
2009 & 226,447 & 128,404 & 92,796 & 11,636 & 248,926 & 804 & 29,384 & 32,827 & 30,362 \\
2010 & 291,702 & 157,963 & 95,529 & 12,068 & 262,443 & 877 & 29,790 & 36,590 & 29,998 \\
2011 & 307,217 & 168,823 & 97,929 & 12,001 & 276,662 & 963 & 33,190 & 40,071 & 32,076 \\
\hline Total & 245,201 & 132,901 & 87,707 & 11,503 & 248,044 & 745 & 31,952 & 31,075 & 26,285 \\
Obs. & 2,568 & 2,568 & 2,568 & 2,568 & 2,568 & 2,568 & 2,568 & 2,506 & 2,244 \\
\hline
\end{tabular}

Median values in deflated thousands of U.S. dollars, except for the absolute number of employees and observations. Specifically, the table presents the median values for the output (column (1)), inputs for the main specification (columns (2) to (4)), inputs used for sensitivity checks (columns (5) to (7)), and R\&D and intangible assets (columns (8) and (9), respectively, which capture the two organization knowledge proxies). Variable definitions: Revenues: gross sales and other operating revenue less discounts, returns and allowances; COGS (cost of goods sold): direct manufacturing cost of material and labor entering in the production of finished goods; Selling, general and administrative expenses: expenses not directly attributable to the production process but relating to selling, general and administrative functions; Depreciation and amortiazation: the process of allocating the cost of a depreciable asset to the accounting periods covered during its expected useful life to a business (depreciation) plus the cost allocation for intangible assets such as patents and leasehold improvements, trademarks, bookplates, tools and film cost (amortization); Operating expenses (other): operating expenses besides cost of goods sold, depreciation, depletion and amortization and selling, general and administrative expense. Employees: number of employees. Fixed assets: tangible piece of property that a firm owns and uses in the production; $R \& D$ (research and development): all direct and indirect costs related to the creation and development of new processes, techniques, applications and products with commercial possibilities; Intangible assets: other assets not having a physical existence.

Table 2: Static performance measures

\begin{tabular}{rrrrrrr}
\hline \multicolumn{2}{r}{ Year Inefficiency } & ROA & ROE & \multicolumn{3}{c}{ ROI Net marg. Op. marg. } \\
\hline 2000 & 0.1441 & 0.0462 & 0.0991 & 0.0850 & 0.0515 & 0.0803 \\
2001 & 0.2145 & -0.0309 & -0.0401 & -0.0337 & -0.0532 & -0.0095 \\
2002 & 0.1590 & -0.0598 & -0.0975 & -0.0702 & -0.0995 & -0.0290 \\
2003 & 0.1735 & -0.0210 & -0.0228 & -0.0137 & -0.0202 & 0.0042 \\
2004 & 0.1646 & 0.0285 & 0.0513 & 0.0460 & 0.0294 & 0.0502 \\
2005 & 0.1767 & 0.0369 & 0.0618 & 0.0576 & 0.0380 & 0.0371 \\
2006 & 0.1370 & 0.0402 & 0.0687 & 0.0626 & 0.0451 & 0.0449 \\
2007 & 0.1655 & 0.0347 & 0.0533 & 0.0519 & 0.0466 & 0.0391 \\
2008 & 0.1553 & 0.0117 & 0.0187 & 0.0185 & 0.0091 & 0.0250 \\
2009 & 0.1533 & -0.0227 & -0.0297 & -0.0258 & -0.0281 & -0.0039 \\
2010 & 0.1821 & 0.0456 & 0.0780 & 0.0728 & 0.0524 & 0.0538 \\
2011 & 0.1840 & 0.0466 & 0.0704 & 0.0688 & 0.0457 & 0.0718 \\
\hline Total & 0.1633 & 0.0174 & 0.0292 & 0.0286 & 0.0160 & 0.0285 \\
Obs. & 2,354 & 2,568 & 2,470 & 2,529 & 2,568 & 2,568 \\
\hline
\end{tabular}

Median values. Inefficiency scores are computed following equation (2) and represent degrees of inefficiency; the lowest values are the best results. The opposite is valid for the accounting ratios, which are interpreted in the traditional fashion: the higher the value, the better the performance. ROA (return on assets): net income divided by total assets; ROE (return on equity): net income divided by shareholders' equity; ROI (return on investment): profit from investment divided by cost of investment; Net margin: net income before preferred dividends divided by net revenues; Operating margin: operating income divided by net revenues. For the efficiency measure, inputs are (i) cost of goods sold (COGS), (ii) selling, general and administrative expenses, and (iii) depreciation and amortization, while the output is revenues. All inputs and the output are variable. 
Table 3: Luenberger decomposition

\begin{tabular}{|c|c|c|c|c|c|c|}
\hline \multicolumn{7}{|c|}{ Panel A: Luenberger indicator } \\
\hline Year & Obs. & Mean & S.D. & Q1 & Median & Q3 \\
\hline 00-01 & 212 & -0.0593 & 0.1071 & -0.1131 & -0.0456 & -0.0066 \\
\hline 01-02 & 214 & -0.0193 & 0.1400 & -0.0913 & -0.0096 & 0.0475 \\
\hline 02-03 & 212 & 0.0409 & 0.0950 & -0.0076 & 0.0338 & 0.0781 \\
\hline 03-04 & 214 & 0.0613 & 0.1218 & 0.0096 & 0.0435 & 0.0828 \\
\hline 04-05 & 214 & 0.0192 & 0.0783 & -0.0230 & 0.0141 & 0.0583 \\
\hline 05-06 & 214 & 0.0131 & 0.0762 & -0.0203 & 0.0089 & 0.0473 \\
\hline $06-07$ & 214 & 0.0006 & 0.0708 & -0.0307 & -0.0001 & 0.0279 \\
\hline 07-08 & 214 & 0.0012 & 0.1130 & -0.0327 & -0.0025 & 0.0283 \\
\hline 08-09 & 214 & -0.0210 & 0.1272 & -0.0653 & -0.0206 & 0.0055 \\
\hline $09-10$ & 214 & 0.0619 & 0.0990 & 0.0036 & 0.0363 & 0.0970 \\
\hline $10-11$ & 213 & 0.0152 & 0.1107 & -0.0283 & 0.0032 & 0.0326 \\
\hline Total & 2349 & 0.0104 & 0.1110 & -0.0342 & 0.0052 & 0.0486 \\
\hline \multicolumn{7}{|c|}{ Panel B: Efficiency change } \\
\hline Year & Obs. & Mean & S.D. & Q1 & Median & Q3 \\
\hline 00-01 & 214 & -0.0676 & 0.1273 & -0.1369 & -0.0375 & 0.0173 \\
\hline 01-02 & 214 & 0.0427 & 0.1483 & -0.0199 & 0.0277 & 0.1284 \\
\hline 02-03 & 214 & 0.0090 & 0.0881 & -0.0331 & 0.0000 & 0.0486 \\
\hline 03-04 & 214 & 0.0025 & 0.0752 & -0.0329 & 0.0000 & 0.0292 \\
\hline 04-05 & 214 & 0.0045 & 0.0719 & -0.0253 & 0.0000 & 0.0430 \\
\hline $05-06$ & 214 & 0.0265 & 0.0732 & 0.0000 & 0.0200 & 0.0631 \\
\hline $06-07$ & 214 & -0.0128 & 0.0581 & -0.0550 & -0.0067 & 0.0126 \\
\hline 07-08 & 214 & 0.0008 & 0.0711 & -0.0257 & 0.0000 & 0.0375 \\
\hline 08-09 & 214 & 0.0047 & 0.0842 & -0.0277 & 0.0000 & 0.0521 \\
\hline 09-10 & 214 & -0.0284 & 0.0894 & -0.0758 & -0.0212 & 0.0145 \\
\hline $10-11$ & 214 & 0.0021 & 0.0645 & -0.0400 & 0.0000 & 0.0293 \\
\hline Total & 2354 & -0.0014 & 0.0942 & -0.0404 & 0.0000 & 0.0399 \\
\hline \multicolumn{7}{|c|}{ Panel C: Frontier change } \\
\hline Year & Obs. & Mean & S.D. & Q1 & Median & Q3 \\
\hline $00-01$ & 212 & 0.0093 & 0.0868 & -0.0408 & -0.0076 & 0.0241 \\
\hline 01-02 & 214 & -0.0620 & 0.0869 & -0.0942 & -0.0573 & -0.0241 \\
\hline 02-03 & 212 & 0.0319 & 0.0656 & 0.0094 & 0.0209 & 0.0409 \\
\hline 03-04 & 214 & 0.0588 & 0.0931 & 0.0304 & 0.0437 & 0.0590 \\
\hline 04-05 & 214 & 0.0147 & 0.0434 & 0.0013 & 0.0105 & 0.0229 \\
\hline 05-06 & 214 & -0.0135 & 0.0397 & -0.0346 & -0.0245 & -0.0057 \\
\hline 06-07 & 214 & 0.0134 & 0.0459 & -0.0029 & 0.0129 & 0.0250 \\
\hline 07-08 & 214 & 0.0004 & 0.0816 & -0.0269 & -0.0056 & 0.0072 \\
\hline 08-09 & 214 & -0.0257 & 0.0962 & -0.0508 & -0.0346 & -0.0129 \\
\hline 09-10 & 214 & 0.0903 & 0.0773 & 0.0431 & 0.0669 & 0.1193 \\
\hline $10-11$ & 213 & 0.0131 & 0.0918 & -0.0143 & 0.0070 & 0.0284 \\
\hline Total & 2349 & 0.0119 & 0.0853 & -0.0257 & 0.0059 & 0.0325 \\
\hline
\end{tabular}

Indicators are computed following equations (4) and (5), and the distance function in equation (2). The reported values represent changes between the periods indicated in the "year" column. Results of zero show no change; positive/negative results show improvement/deterioration. The number of observations for the Luenberger indicator and the frontier change is slightly lower than for the efficiency change due to the presence of infeasible results for five of the analyzed firms. Inputs are (i) cost of goods sold (COGS), (ii) selling, general and administrative expenses, and (iii) depreciation and amortization, while the output is revenues. All inputs and the output are variable. For the Luenberger indicator and the frontier change component, there are fewer observations in periods 2000-2001, 2002-2003 (two observations less in each period) and 2010-2011 (one observation less) due to the presence of infeasible results. Note that these observations amount to only $0.2 \%$ of the sample. 
Table 4: Changes in ROA and net margin (descriptive statistics)

\begin{tabular}{rrrrrrr}
\hline \multicolumn{2}{c}{ Panel A: } & \multicolumn{1}{c}{ ROA } & & & & \\
Year & Obs. & Mean & S.D. & Q1 & Median & Q3 \\
\hline $00-01$ & 214 & -0.1489 & 0.5973 & -0.2192 & -0.0982 & -0.0130 \\
$01-02$ & 214 & -0.0260 & 0.4857 & -0.1270 & -0.0282 & 0.0823 \\
$02-03$ & 214 & 0.1282 & 0.4084 & -0.0167 & 0.0329 & 0.1570 \\
$03-04$ & 214 & 0.0359 & 0.5203 & 0.0047 & 0.0389 & 0.1025 \\
$04-05$ & 214 & 0.0288 & 0.2907 & -0.0309 & 0.0084 & 0.0449 \\
$05-06$ & 214 & 0.0105 & 0.3765 & -0.0422 & 0.0019 & 0.0531 \\
$06-07$ & 214 & 0.0095 & 0.1881 & -0.0362 & 0.0002 & 0.0364 \\
$07-08$ & 214 & -0.0893 & 0.3364 & -0.1523 & -0.0199 & 0.0153 \\
$08-09$ & 214 & -0.0332 & 0.4040 & -0.1113 & -0.0303 & 0.0565 \\
$09-10$ & 214 & 0.1536 & 0.3979 & 0.0105 & 0.0643 & 0.1901 \\
$10-11$ & 214 & -0.0213 & 0.2586 & -0.0553 & -0.0043 & 0.0426 \\
Total & 2354 & 0.0043 & 0.4112 & -0.0643 & 0.0020 & 0.0694 \\
\hline Panel B: & $\Delta$ Net margin & & & & \\
Year & Obs. & Mean & S.D. & Q1 & Median & Q3 \\
\hline $00-01$ & 214 & -0.2519 & 1.5506 & -0.3310 & -0.1056 & -0.0016 \\
$01-02$ & 214 & -0.1927 & 2.0495 & -0.2028 & -0.0177 & 0.0999 \\
$02-03$ & 214 & 0.3336 & 1.7782 & -0.0187 & 0.0456 & 0.3107 \\
$03-04$ & 214 & 0.2462 & 1.1628 & 0.0091 & 0.0593 & 0.2025 \\
$04-05$ & 214 & 0.0204 & 0.7348 & -0.0394 & 0.0083 & 0.0699 \\
$05-06$ & 214 & -0.0480 & 0.7511 & -0.0517 & 0.0047 & 0.0858 \\
$06-07$ & 214 & 0.1143 & 1.3676 & -0.0454 & -0.0016 & 0.0603 \\
$07-08$ & 214 & -0.1060 & 0.7308 & -0.1560 & -0.0225 & 0.0142 \\
$08-09$ & 214 & -0.0698 & 1.0120 & -0.1558 & -0.0181 & 0.0537 \\
$09-10$ & 214 & 0.2237 & 0.6549 & 0.0102 & 0.0939 & 0.2275 \\
$10-11$ & 214 & -0.0247 & 0.3040 & -0.0572 & -0.0017 & 0.0540 \\
Total & 2354 & 0.0223 & 1.2230 & -0.0741 & 0.0041 & 0.0953 \\
\hline
\end{tabular}

ROA (return on assets): net income divided by total assets; Net margin: net income before preferred dividends divided by net revenues. The reported values represent changes between the periods indicated in the "year" column. Results of zero show no change; positive/negative results show improvement/deterioration.

Table 5: Regression results

\begin{tabular}{|c|c|c|c|c|c|}
\hline & $\begin{array}{c}\text { Luenberger } \\
\text { indicator } \\
(t \text { to } t+1) \\
(1) \\
\end{array}$ & $\begin{array}{c}\text { Efficiency } \\
\text { change (EC) } \\
(t \text { to } t+1) \\
(2) \\
\end{array}$ & $\begin{array}{c}\text { Frontier } \\
\text { change (FC) } \\
(t \text { to } t+1) \\
(3) \\
\end{array}$ & $\begin{array}{c}\Delta \mathrm{ROA} \\
(t \text { to } t+1) \\
(4) \\
\end{array}$ & $\begin{array}{c}\Delta \text { Net margin } \\
(t \text { to } t+1) \\
(5) \\
\end{array}$ \\
\hline$\Delta \mathrm{R} \& \mathrm{D}(t-1$ to $t)$ & $\begin{array}{r}-.0000792 \\
(.000124)\end{array}$ & $\begin{array}{l}-.0003821 * * \\
(.000152)\end{array}$ & $\begin{array}{l}.0003015 * * \\
(.000120)\end{array}$ & $\begin{array}{l}.0013086 * * \\
(.000601)\end{array}$ & $\begin{array}{l}.0063320 * * \\
(.002631)\end{array}$ \\
\hline$\Delta$ Intang. $(t-1$ to $t)$ & $\begin{array}{l}.0000534^{* * *} \\
(.000020)\end{array}$ & $\begin{array}{l}.0000396 \\
(.000034)\end{array}$ & $\begin{array}{l}.0000139 \\
(.000018)\end{array}$ & $\begin{array}{r}-.0005970 \\
(.000363)\end{array}$ & $\begin{array}{l}-.0024981 * \\
(.001483)\end{array}$ \\
\hline $\operatorname{lnTA}(t-1)$ & $\begin{array}{l}-.0411109 * * * \\
(.010064)\end{array}$ & $\begin{array}{l}-.0272012 * * * \\
(.005930)\end{array}$ & $\begin{array}{r}-.0137067 \\
(.009313)\end{array}$ & $\begin{array}{l}-.0840833 * * \\
(.033473)\end{array}$ & $\begin{array}{l}.0391468 \\
(.097228)\end{array}$ \\
\hline Liab./TA $(t-1)$ & $\begin{array}{l}.0037450 \\
(.025422)\end{array}$ & $\begin{array}{r}.0045823 \\
(.015134)\end{array}$ & $\begin{array}{r}-.0007621 \\
(.013340)\end{array}$ & $\begin{array}{l}.2742752 \text { *** } \\
(.081640)\end{array}$ & $\begin{array}{l}.1510644 \\
(.065205)\end{array}$ \\
\hline Firm fixed effects & Yes & Yes & Yes & Yes & Yes \\
\hline Year effects & Yes & Yes & Yes & Yes & Yes \\
\hline _cons & $\begin{array}{l}.5659547^{* * *} \\
(.13203)\end{array}$ & $\begin{array}{l}.3520503 * * * \\
(.076762)\end{array}$ & $\begin{array}{l}.2109370 * \\
(.121097)\end{array}$ & $\begin{array}{l}1.106689 * * * \\
(.420626)\end{array}$ & $\begin{array}{l}-.0742345 * * * \\
(1.19573)\end{array}$ \\
\hline $\mathrm{F}$ & $11.26 * * *$ & $10.30 * * *$ & $60.88 * * *$ & $9.03 * * *$ & $6.73 * * *$ \\
\hline R-sq & 0.104 & 0.087 & 0.296 & 0.144 & 0.108 \\
\hline Observations & 1727 & 1729 & 1727 & 1729 & 1729 \\
\hline
\end{tabular}

$* \mathrm{p}<0.10, * * \mathrm{p}<0.05, * * * \mathrm{p}<0.01$. Fixed effects panel data regression (equation (8) in Section 4.2.). Robust standard errors are reported in brackets. Indicators are computed following equations (4) and (5), and the distance function in equation (2); ROA (return on assets): net income divided by total assets; Net margin: net income before preferred dividends divided by net revenues. Changes in R\&D and intangibles computed using the reported values $\times 0.0001$. For the Luenberger indicator, and efficiency and frontier changes, inputs are (i) cost of goods sold (COGS), (ii) selling, general and administrative expenses, and (iii) depreciation and amortization, while the output is revenues. All inputs and the output are variable. For the Luenberger indicator and the frontier change component there are two observations less due to infeasible results. 


\section{APPENDIX: SENSITIVITY CHECKS}

\section{Accounting for variable and fixed inputs}

Separate the vector of inputs $\mathbf{x}=\left(x_{1}, \ldots, x_{N}\right) \in R_{+}^{N}$ into a vector of variable inputs $\mathbf{x}_{\mathbf{v}}=\left(x_{v 1}, \ldots, x_{v p}\right) \in R_{+}^{P}$ and a vector of fixed inputs $\left(\mathbf{x}_{\mathbf{f}}=\left(x_{f 1}, \ldots, x_{f J}\right) \in R_{+}^{J}\right)$. The output vector maintains its initial specification $\left(\mathbf{y}=\left(y_{1}, \ldots, y_{M}\right) \in R_{+}^{M}\right)$. Technology is now defined by the set $T^{t}\left(\mathbf{x}_{\mathbf{f}}^{\mathbf{t}}, \mathbf{x}_{\mathbf{v}}^{\mathbf{t}}, \mathbf{y}^{\mathbf{t}}\right)$, which represents the set of all feasible output vectors $\left(\mathbf{y}^{\mathbf{t}}\right)$ that can be produced using the variable $\left(\mathbf{x}_{\mathbf{v}}{ }^{\mathbf{t}}\right)$ and fixed $\left(\mathbf{x}_{\mathbf{f}}^{\mathbf{t}}\right)$ input vectors in the time period $t$ : $T^{t}\left(\mathbf{x}_{\mathbf{f}}^{\mathbf{t}}, \mathbf{x}_{\mathbf{v}}^{\mathbf{t}}, \mathbf{y}^{\mathbf{t}}\right)=\left\{\left(\mathbf{x}_{\mathbf{f}}^{\mathbf{t}}, \mathbf{x}_{\mathbf{v}}^{\mathbf{t}}, \mathbf{y}^{\mathbf{t}}\right): \mathbf{x}_{\mathbf{f}}^{\mathbf{t}}\right.$ and $\mathbf{x}_{\mathbf{v}}^{\mathbf{t}}$ can produce $\left.\mathbf{y}^{\mathbf{t}}\right\}$.

To estimate the inefficiency of firm $k$, the linear programming problem that expands outputs, contracts variable inputs, and accounts for fixed inputs-without contracting them-is now:

$$
\begin{aligned}
D^{t}\left(x_{v}^{t}, x_{f}^{t}, y^{t}\right)= & \max \\
& \left\{\delta: \sum_{k=1}^{K} \lambda_{k}^{t} y_{k m}^{t} \geq y_{k^{\prime} m}^{t}+\delta y_{k^{\prime} m}^{t}, m=1,2, \ldots, M,\right. \\
& \sum_{k=1}^{K} \lambda_{k}^{t} x_{v k p}^{t} \leq x_{v k^{\prime} p}^{t}-\delta x_{v k^{\prime} p}^{t}, \mathrm{p}=1,2, \ldots, P, \\
& \sum_{k=1}^{K} \lambda_{k}^{t} x_{f k j}^{t} \leq x_{f k^{\prime} j}^{t}, \mathrm{j}=1,2, \ldots, J, \\
& \left.\sum_{k=1}^{K} \lambda_{k}=1, \lambda_{k} \geq 0, \quad(k=1,2, \ldots, K)\right\} .
\end{aligned}
$$




\section{APPENDIX FIGURES}

Figure A1: Sensitivity checks of the Luenberger decomposition
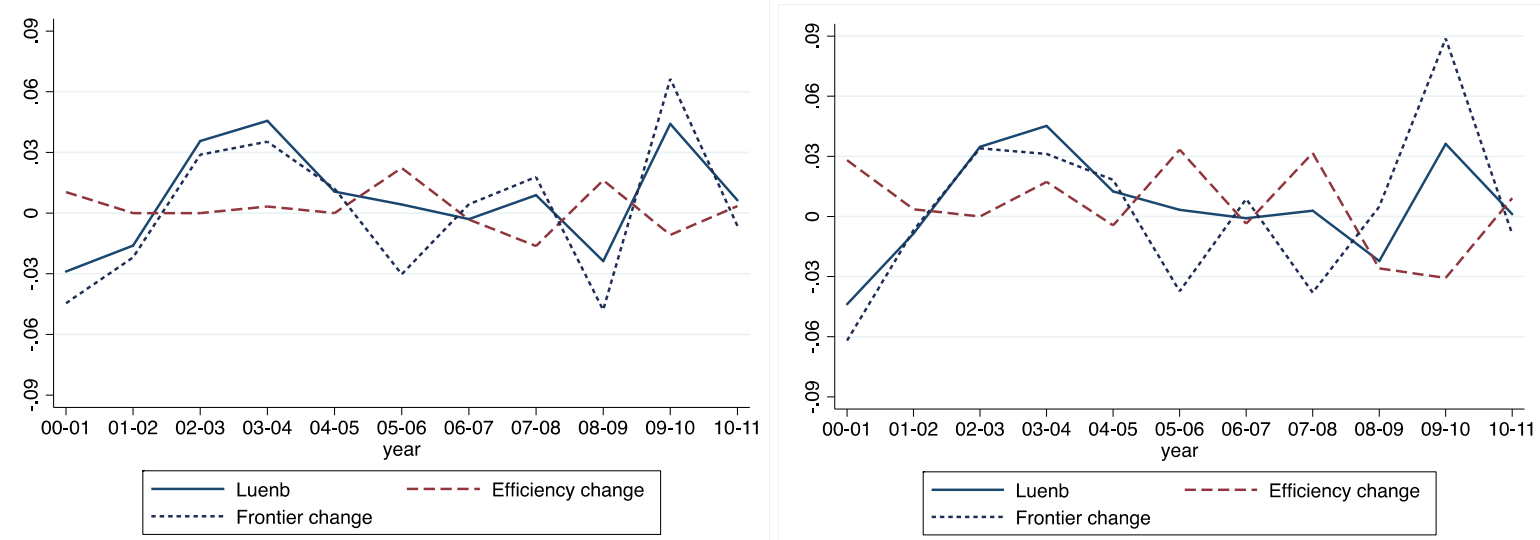

Indicators are computed following equations (4) and (5), and the distance function in equation (A2). All values represent changes at median level between the periods indicated on the horizontal axis. Results of zero show no change; positive/negative results show improvement/deterioration. For the alternative model 1 (top left), variable inputs are cost of goods sold (COGS) and selling, general and administrative expenses, the fixed input is fixed assets, while the output is revenues. For the alternative model 2 (bottom), the variable input is operating expenses, the fixed inputs are fixed assets and the number of employees, while the output is revenues. 